\title{
El Aziliense de Cueva Oscura de Ania (Las Regueras, Asturias): primera aproximación y su contexto en la cuenca del Nalón
}

\author{
Gema Elvira adán Álvarez *, Eduardo García Sánchez ** \\ Y José Manuel Quesada López ***
}

\begin{abstract}
RESUMEN ABSTRACT
La revisión crítica de los materiales arqueológicos exhumados en Cueva Oscura de Ania ha permitido definir las características generales de su

depósito Aziliense, al tiempo que incorporar definitivamente esta cueva a la nómina de yacimientos donde se documenta un horizonte de transición entre el Magdaleniense superior final y

el Aziliense clásico, conocido como Aziliense antiguo. Se aprovecha esta circunstancia para realizar una sintesis

historiográfica sobre el conocimiento del origen y el desarrollo del Aziliense

en la cuenca hidrográfica del Nalón.

PALABRAS CLAVE

Cueva Oscura de Ania; Aziliense antiguo; Aziliense clásico; Paleolítico superior final; Epipaleolítico; Cuenca del

Nalón; Asturias; Cornisa Cantábrica.

A critic review of the archaeological record from Cueva Oscura de Ania has allowed us explain the nature of her Azilian levels. This cave can be included in the group of sites where it is found a transitional period from Upper Magdalenien to Classic Azilian, labelled as Older Azilian. In this paper it is also introduced a regional sinthesis about the archaeological knowledge of the Azilian in the asturian Nalón basin.

\section{KEYWORDS}

Cueva Oscura de Ania; Older Azilian; Classic Azilian; Upper Paleolithic; Epipaleolithic; Nalón Basin; Asturias; Cantabric region.

* Doctora en Prehistoria por la Universidad de Salamanca.

** Becario Predoctoral UNED. Departamento de Prehistoria e Historia Antigua. Facultad de Geografía e Historia. UNED c/ Senda del Rey, s/n; 28047 Madrid. Correo electrónico: I.garcia3@cgac.es

*** Becario Postdoctoral Comunidad de Madrid. Departamento de Prehistoria e Historia Antigua. Facultad de Geografía e Historia. UNED c/ Senda del Rey, s/n; 28047 Madrid. Correo electrónico: jmquesada@inicia.es.
\end{abstract}




\section{INTRODUCCIÓN}

La documentación disponible hasta la fecha para el aziliense en la cuenca del Nalón resultaba relativamente reducida. En líneas generales, se trataba de un registro arqueológico bastante escaso, con un carácter disperso y una entidad discreta, lo que dificultaba una aproximación siquiera somera a los rasgos esenciales de este período. Un ejemplo de esta situación es el caso de Cueva Oscura de Ania (Ania, Las Regueras), excavada durante la segunda mitad de la década de 1970, cuyo interesante registro se encuentra prácticamente inédito y no ha sido recogido y contextualizado en una monografía que le haga justicia. El presente artículo es un primer avance, centrado en los niveles azilienses de la cueva, de los resultados de una revisión de los materiales arqueológicos exhumados por los mencionados trabajos de campo, en la actualidad depositados en el Museo Arqueológico de Asturias (Oviedo). Nuestro estudio da pie para perfilar nuevas hipótesis sobre el estado de la cuestión en el estudio del Aziliense en la cuenca del Nalón.

\section{EL AZILIENSE EN LA CUENCA DEL NALÓN: UNA CUESTIÓN PENDIENTE}

El grueso del registro aziliense disponible para la extensa cuenca hidrográfica del Nalón está constituido en su mayor parte por conjuntos parciales, fruto de excavaciones antiguas. Éstos adolecen de la pérdida de información inherente a la metodología aplicada en su momento, como es el caso de la Cueva de la Paloma (Soto de Las Regueras). Tal panorama se completa con noticias vagas e imprecisas de trabajos de campo prácticamente desconocidos de mediados de la década de 1960, caso de Cueva Oscura de Perán (Perlora, Carreño), o con referencias provisionales, alusiones o citas genéricas procedentes de investigaciones más recientes, situación en la que se encuentran la misma Cueva Oscura de Ania, la Cueva de La Lluera I (San Juan de Priorio, Oviedo) y la Cueva del Ángel (Santo Adriano, Tuñón). A ello se unen algunos depósitos antiguos no exentos de polémica por las dificultades para deslindar siquiera los niveles azilienses de los magdalenienses $e$, incluso, filiaciones erróneas debidas a las vicisitudes singulares experimentadas por los materiales desde el momento de su excavación hasta la actualidad. En suma, un conjunto aparentemente inconexo de informaciones con una génesis historiográfica dispar que parece convertir el Aziliense en la cuenca del Nalón en un período oscuro. 


\subsection{Investigaciones pioneras: el primer tercio del Siglo $x x$}

Hasta hace unos años, el registro aziliense más relevante en la cuenca del Nalón derivaba de las distintas revisiones de los materiales exhumados en las antiguas excavaciones de la Cueva de La Paloma (FernándezTresguerres Velasco 1980; Hoyos Gómez et alii 1980). Sobre estos exámenes descansaba la definición del aziliense y la caracterización de los rasgos esenciales de su industria en esta región asturiana. Estos trabajos de campo, realizados entre 1914 y 1915 por Eduardo Hernández Pacheco, sacaron a la luz una importante sucesión de niveles arqueológicos que corresponderían al periodo comprendido entre el Magdaleniense inferior cantábrico y el Aziliense, "con tránsito insensible de uno a otro nivel» (Hernández Pacheco 1954: 7), además de un nivel superficial postpaleolítico revuelto («neolítico y de las épocas de los metales»; Hernández Pacheco 1922: 336). Coetáneas a la excavación de la Cueva de la Paloma fueron las investigaciones realizadas en el Nalón por D. Ricardo Duque de Estrada, Conde de la Vega del Sella (Rasilla Vives 1991). En ellas destacan los trabajos de campo en la Cueva de Sofoxó I (Rañeces, Las Regueras), descubierta para la arqueología por el Conde de la Vega del Sella en 1916. Éste, aún considerando revuelto el yacimiento, documentó la existencia de un momento de transición entre el Magdaleniense y el Aziliense (Vega del Sella 1921: 69). Hugo Obermaier, que colaboró en los trabajos de campo, rnencionó indicios azilienses y un nivel Magdaleniense superior (Obermaier 1925: 190), mientras que Hernández Pacheco citó un nivel Aziliense sin arpones típicos o «Magdalo-aziliense» superpuesto a otro del Magdaleniense inferior (Hernández Pacheco 1919).

Las notables dificultades para definir con precisión Sofoxó I acabó convirtiendo la Cueva de la Paloma en el yacimiento aziliense clave en la cuenca del Nalón. En realidad, la importancia de esta última en los estudios sobre el Aziliense cantábrico fue transcendental a juzgar por las primeras valoraciones de su registro. El magnífico trabajo firmado por Vega del Sella (1917) sobre la evolución de las industrias paleolíticas asturianas recurría a La Paloma como una secuencia modelo para esbozar la primera cronoestratigrafía de las industrias azilienses, sirviendo para definir dos estadios sucesivos: una primera etapa conocida como «Aziliense A» y una segunda denominada «Aziliense B». La primera de ellas estaría caracterizada por pequeños raspadores nucleiformes y cónicos, disquitos raspadores típicos, hojas alargadas y microlitos muy abundantes, pero sin geométricos. Por su parte, la segunda o «Aziliense B», se definiría por una mayor presencia del "disco raspador", "hojas de dorso rebajado» y el "arpón aplastado de esquirla de hueso, con perforación en la base». 
Sin embargo, la singular relevancia del registro de La Paloma en la definición del Aziliense cantábrico cayó pronto en descrédito como consecuencia del anatema lanzado sobre el yacimiento por Hugo Obermaier (1925) tras su polémica con Hernández Pacheco en torno a una posible contaminación de los materiales. En puridad, desde un principio los resultados de la excavación no tuvieron una gran difusión: apenas una breve memoria redactada para el Homenaje a Santiago Ramón y Cajal, publicada en la serie de la Comisión de Investigaciones Paleontológica y Prehistórica (Hernández Pacheco 1923a); un par de noticias sobre piezas concretas de arte mueble (Hernández Pacheco 1922, 1923b); la citada alusión al conjunto ergológico del yacimiento (Vega del Sella 1917) y una referencia a los restos humanos exhumados (Eguren 1919). Esta escasez de noticias y la ausencia de una memoria con más enjundia que aportara datos concretos sobre su estratigrafía y registro hizo que la comunidad científica terminara por canonizar las opiniones de Hugo Obermaier. Éste, defendiendo su división del Magdaleniense cantábrico sobre la base de Castillo y Cueto de la Mina, mantenía que el depósito de la Paloma estaba "completamente revuelto por un buscador de tesoros» y la secuencia establecida por Hernández Pacheco (1923a) constituía una "reconstrucción teórica» inútil para «comprobar el tránsito del Magdaleniense al Aziliense» (Obermaier 1925: 190-191). De esta manera, dados los problemas de interpretación ocasionados por la Cueva de Sofoxó I y el descrédito en el que cayeron los trabajos de Hernández Pacheco en la Cueva de la Päloma, la cuenca del Nalón mantuvo una posición marginal en las síntesis del primer tercio del siglo $\mathrm{xx}$.

\subsection{La Postguerra española}

Tras el paréntesis impuesto en los estudios paleolíticos por la Guerra Civil española (1936-1939), la atención prestada al Aziliense cantábrico se constriñó a cuestiones teóricas de génesis cultural (véase Martínez Santaolalla 1941, 1946; Almagro-Basch 1944, 1963). En este contexto de postguerra, tan sólo se recogen algunas alusiones a la cueva de La Paloma, pequeñas citas o meras referencias (Jordá Cerdá 1957; González Echegaray 1966) que en ninguno de los casos mencionan el depósito aziliense. Al margen de estas discusiones, durante estos años no se constatan avances significativos en el conocimiento del Aziliense Cantábrico. Baste como ejemplo la síntesis de Hernández Pacheco (1959), donde se limita a retomar las propuestas clásicas sin aportar planteamientos alternativos al respecto (Fernández-Tresguerres Velasco 1980: 26). El desinterés 
mostrado durante esta época y los años inmediatamente posteriores hacia el Aziliense queda patente, en el caso concreto de la cuenca del Nalón, tanto en la escasa difusión de las excavaciones realizadas en Cueva Oscura de Perán (Fernández Rapado \& Mallo Viesca 1965), donde se documentó un nivel aziliense, como en el hecho de que desde el descubrimiento en 1958 del depósito de Cueva Oscura de Ania hasta su excavación transcurrieran más de quince años (Pérez Pérez 1977: 180).

En este parco contexto, los únicos trabajos con cierta enjundia fueron los acometidos entre 1952 y 1964 por Francisco Jordá, al frente del Servicio de Investigaciones Arqueológicas de Asturias (Adán Álvarez en prensa). Como parte de los mismos, se retomaron las investigaciones del Conde de la Vega del Sella en las cuencas del Nalón y el Sella. En esta última se excavaron y/o acondicionaron las Cuevas de Tuñón (Santo Adriano), Peña de Candamo (San Román de Candamo) y Oscura de Perlora (Carreño) y se realizaron visitas de evaluación a Sofoxó I y La Paloma (Jordá Cerdá 1963; 1976). En Cueva Oscura de Perlora determinó la presencia de un nivel magdaleniense caracterizado por «varias hojas largas, hojitas de borde rebajado, varios tipos de raspadores y buriles, huesos aguzados, una azagaya biapuntada y la punta de otra" (Jordá Cerdá 1976: 103) y una fase Aziliense con «Arpones típicos» (ibidem: 112).

\subsection{Investigaciones modernas: el último tercio del Siglo $x x$}

El descrédito en el que cayó la Cueva de la Paloma perduró hasta comienzos de la década de 1970. En aquellos años Soledad Corchón (1971) e Ignacio Barandiarán $(1971,1973)$ estudiaron sus materiales con más detenimiento, revalorizando su registro. La constatación de niveles intactos en los cortes estratigráficos favoreció decisivamente su reivindicación: a finales de los setenta se desarrolló un trabajo en equipo que fructificó en una memoria que integraba estudios geológicos, paleontológicos y arqueológicos (Hoyos Gómez et alii 1980) y un análisis bastante exhaustivo de los diarios de Hernández Pacheco y Paul Wernert. Al mismo tiempo, Juan Fernández-Tresguerres (1980: 59-74) realizó una revisión propia de los materiales azilienses de la cueva como parte de su visión de conjunto del Aziliense cantábrico, promovida por la investigación que inició en 1973 en el yacimiento aziliense más emblemático de la cornisa cantábrica: la Cueva de Los Azules (Cangas de Onís).

Durante la década de 1970 José Manuel Gómez Tabanera, al frente del Seminario de Prehistoria de la Universidad de Oviedo, inició un proyecto de investigación en la cuenca del Nalón (Gómez Tabanera 1975a). En su propuesta citó la presencia de Aziliense en las cuevas de Mestas III o del Gitano 
(Taoces, Regueras) y La Paloma. En la primera evaluó un corte realizado en el transcurso de las obras acometidas por Hidroeléctrica del Cantábrico, apreciando "adheridos restos de un yacimiento que cabe considerar aziliense, y en el que al parecer hace algunos años, fue recogido un fragmento de arpón plano unilateral y pluridentado" (Gómez Tabanera 1975: 75). A continuación, describe la estratigrafía de la cueva que le facilitó M. Pérez cuando la observó en 1969 (ibidem: 75 y 76): Nivel I, «Un metro de potencia, de base arenosa y color amarillento, con bastantes lascas y núcleos, así como algunos útiles de pequeño tamaño, propios del Magdaleniense final o del Aziliense»; Nivel II, Magdaleniense; Nivel III, Auriñaciense y Nivel IV, sin perfilar. En cuanto a la Cueva de la Paloma, según sus datos estarían representados un Magdaleniense Inferior; un Magdaleniense Final, con fases del Aziliense y un postpaleolítico que incluye del Neolítico a Edad de los Metales (ibidem: 83). Su propuesta también citaba Cueva Oscura de Ania, aunque su mención no va más allá de enumerar los integrantes del equipo por él dirigido.

Justamente a finales de la década de 1970 se desarrollan nuevas excavaciones en la Cueva de La Paloma, a cargo de Julián Bécares (Jordá Cerdá 1980: 12). Éstas se centraron en algunas de las zonas del yacimiento protegidas por el desprendimiento de grandes bloques (Julián Bécares, comunicación personal).

Este conocimiento del Aziliense en el Nalón se ha visto ampliado en los últimos años con excavaciones en la Cueva del Ángel (Tuñón, Santo Adriano) y la Cueva de La Lluera I (San Juan de Priorio, Oviedo), si bien las noticias disponibles hasta la fecha no pasan de ofrecer una contextualización estratigráfica genérica y algunas breves referencias sobre los materiales exhumados. De la Cueva del Ángel poco más puede añadirse sobre su registro, a causa del estado en que se encontraba el yacimiento cuando se realizaron excavaciones de urgencia en 1990 (Adán Álvarez 1995: 309-315; 1997: 55-57; Adán Álvarez \& Jordá Pardo 1992). En cuanto a Lluera I, cavidad de dimensiones reducidas situada en la margen derecha del río Nalón, fue excavada entre 1980 y 1985 por José A. Rodríguez Asensio en el marco del Plan General de Estudio de la Cuenca Media del Nalón, dirigido por Javier Fortea (Fortea Pérez 1981; Rodríguez Asensio 1990) y su registro aún aguarda una publicación detallada.

\section{EL REGISTRO AZILIENSE EN LA CUENCA DEL NALÓN: ESTADO DE LA CUESTIÓN}

Así las cosas, el registro aziliense de la cuenca del Nalón puede calificarse como disperso y de entidad discreta, salvando las excepciones de la 


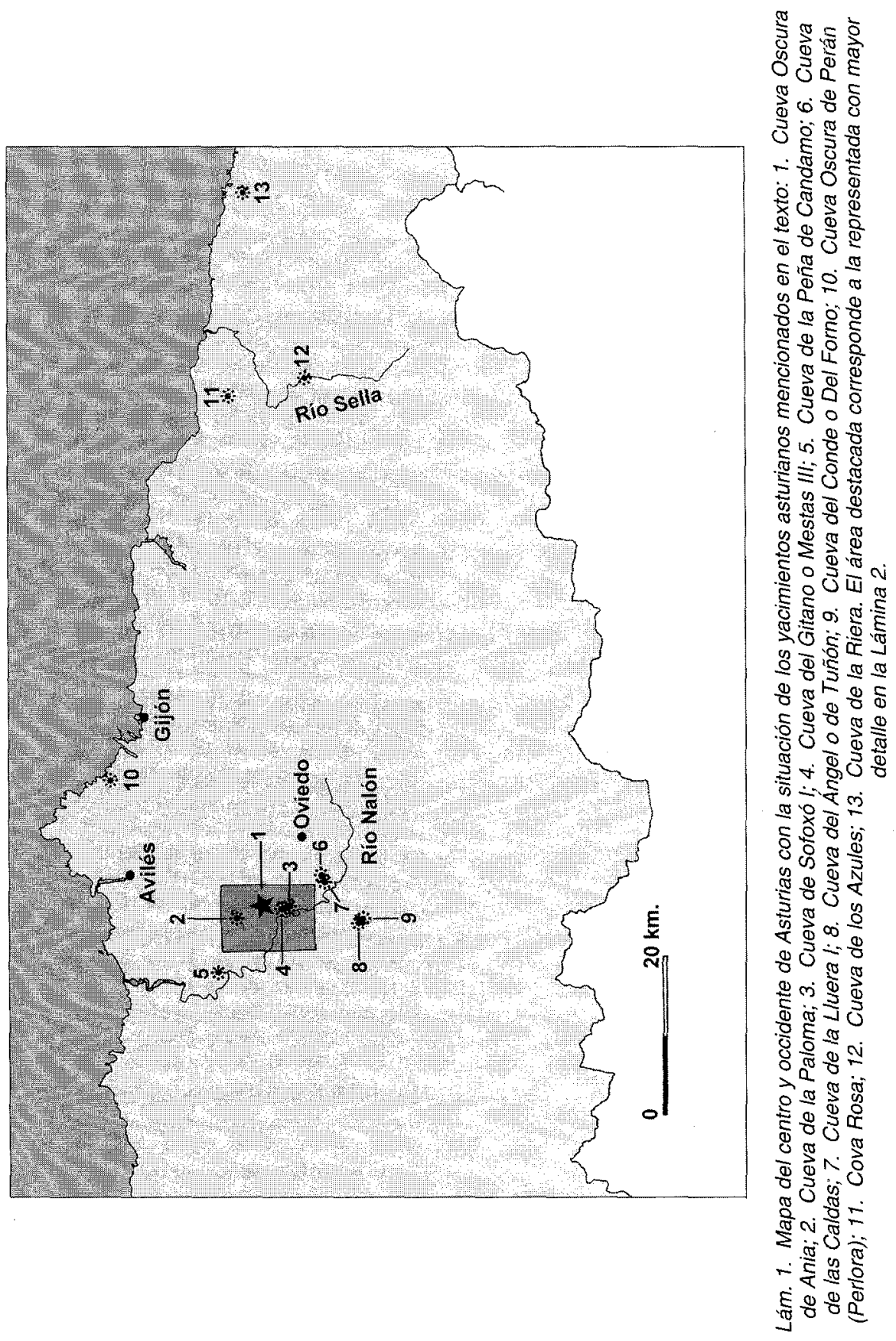


Cueva de la Paloma y las noticias disponibles de la Cueva de La Lluera I. Tan sólo en un yacimiento más, Cueva Oscura de Perán, se constata sin dudas razonables la presencia de niveles azilienses. Las noticias sobre la existencia de vestigios de este periodo en los depósitos de la Cueva del Ángel, la Cueva de Sofoxó I y la Cueva de la Peña de Candamo (San Román, Candamo) resultan problemáticas a la hora de abordarlas y las revisiones más recientes de sus respectivas colecciones aconsejan prudencia en el mejor de los casos. Detengámonos un poco en cada yacimiento (Lám. 2).

\subsection{La Paloma (Soto de las Regueras)}

Los trabajos originales en la cueva de La Paloma documentaron un único depósito aziliense (Nivel 2). Las exploraciones realizadas en la parte intacta del yacimiento exhumaron un nivel de tierra negra de unos $30 \mathrm{~cm}$. de espesor máximo, «un importante conjunto, de magdaleniense y aziliense, con tránsito insensible de uno a otro nivel" (Hernández Pacheco 1954: 7). En tiempos más recientes, la revisión del registro determinó que, si bien no está claro que pueda documentarse con fiabilidad la transición del Magdaleniense superior al Aziliense, el depósito en cuestión estaba intacto en su mayor parte (Fernández-Tresguerres Velasco 1980: 59-74; Hoyos Gómez et alii 1980).

Las primeras noticias sobre el conjunto lítico aziliense de La Paloma señalan la presencia de numerosas hojitas de dorso rebajado y «disquitosraspador» (Hernández Pacheco 1922: 336). Las dos revisiones efectuadas sobre estos materiales ratifican las opiniones originales: en este estrato se documenta una industria con abundancia de pequeños raspadores circulares y unguiformes, escasez de buriles y una nutrida representación del utillaje microlaminar. Bien es cierto que la presencia de laminillas azilienses resultó más exigua de lo que se esperaba (Martínez Navarrete \& Chapa Brunet 1980: 199). En general, los índices del grupo microlaminar son bajos en toda la secuencia del yacimiento, pero esta circunstancia no debería extrañar si se atiende a la época en que éste se excavó (FernándezTresguerres Velasco 1980: 70). Se ha elogiado la meticulosidad de los métodos de trabajo puestos en práctica por Hernández Pacheco en La Paloma, pero siempre entendiendo el contexto histórico y los criterios de investigación que los rodearon (Martínez Navarrete \& Chapa Brunet 1980: 198). En cualquier caso, el conjunto lítico del nivel 2 de la Cueva de La Paloma no desentona con los que se conocen de las fases más antiguas del Aziliense y presenta escasas diferencias con el correspondiente al Magdaleniense superior al que se superpone (ibidem: 139). 


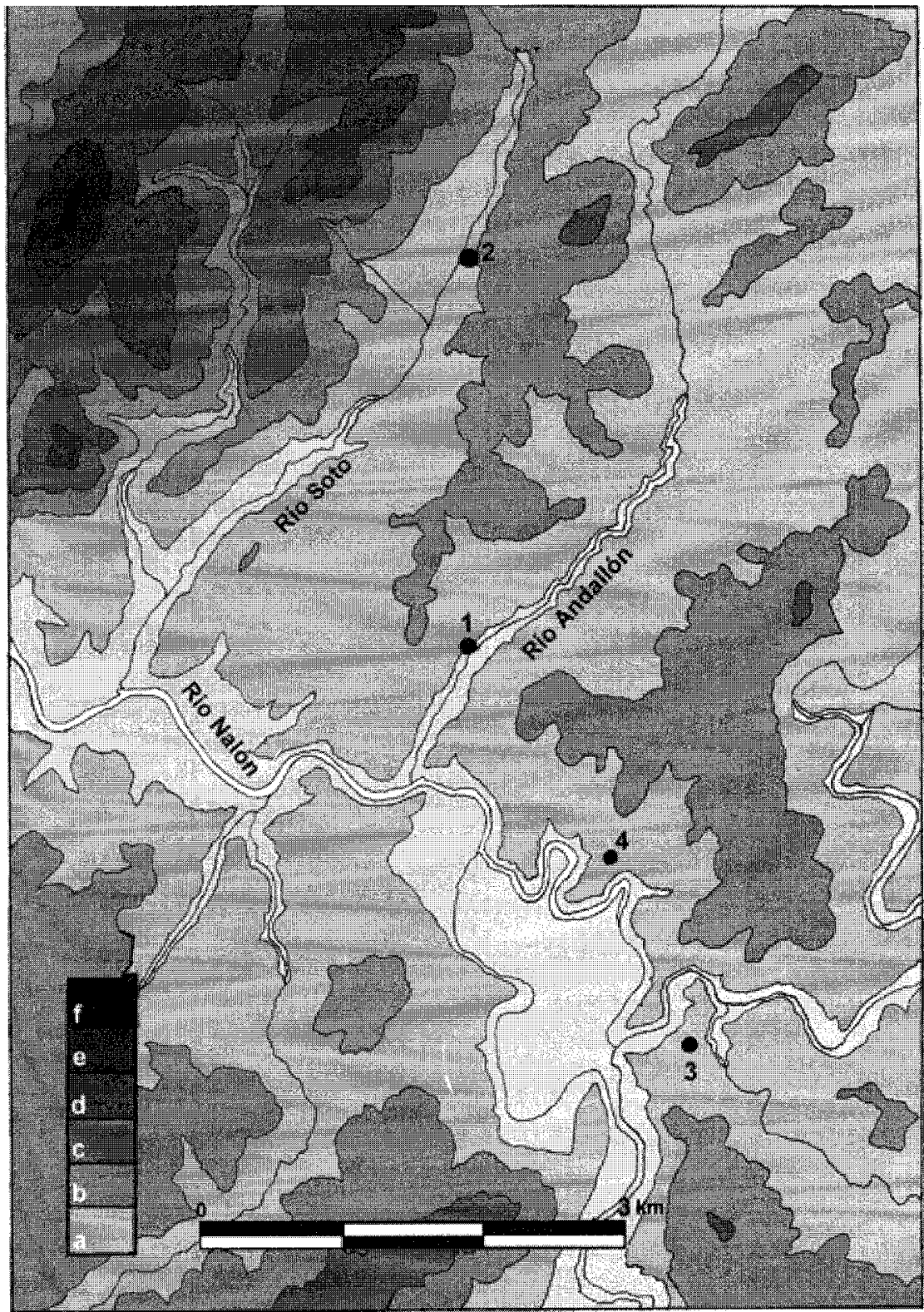

Lám. 2. Tramo del curso medio del río Nalón y ubicación de yacimientos que presentan depósitos claros o indicios azilienses: 1 . Cueva Oscura de Ania; 2 . Cueva de la Paloma;

3. Cueva de Sofoxó $1 ; 4$. Cueva del Gitano o Mestas III. Curvas de nivel (m. s. n. m.): a- 0 100; b- 100-200; c- 200-300; d-300-400; e- 400-500; $f$ - 500-600. 
En cuanto al utillaje óseo, el pequeño tamaño de la muestra no permite extraer conclusiones más allá de ser consecuentes con las características supuestas a los contextos azilienses. En la colección destacan un Arpón plano con una hilera de dientes y perforación circular, que define el nivel, y un fragmento que pudiera ser proximal de Propulsor o distal de Arpón plano con decoración. La morfología de la perforación del Arpón, las decoraciones presentes en algunas Azagayas, un Punzón, el presunto Propulsor y los Colgantes apuntan hacia un Aziliense temprano (Fernández-Tresguerres Velasco 1994), algo en consonancia con los resultados del estudio tecnomorfológico del conjunto óseo conservado (Adán Álvarez 1997). Por lo demás, en su momento llamó la atención la nutrida representación (19 ejemplares) de caninos atróficos de ciervo perforados (ibidem: 139), tradicionalmente clasificados como Colgantes, pues se suponia que el Aziliense representaba una fase de retroceso de este tipo de piezas (Barandiarán Maestu 1968: 282). Enrique Eguren (1919: 30) y Hernández Pacheco $(1923: 549,567)$ mencionan restos de dientes y maxilares humanos y un enterramiento infantil del que Barandiarán Maestu (1988) ofrece una datación de $11.990 \pm 140$ BP y otra del nivel Magdaleniense superior/Aziliense de $12.500 \pm 140 \mathrm{BP}$. No se han localizado referencias a una posible asociación de estos despojos humanos con los caninos atróficos perforados. Sin embargo, el grueso de éstos últimos y los restos paleoantropológicos se guardan en una misma caja y poseen números de inventario correlativos en la institución que conserva los materiales de la Cueva de la Paloma excavados por Hernández Pacheco, el Museo Nacional de Ciencias Naturales de Madrid. Ante esto, la imaginación nos lleva a una sugerente hipótesis: que estos elementos de adornos formaran parte del ajuar funerario de un enterramiento que bien no supo identificarse con claridad en el momento de la excavación, bien había sido alterado por las actividades del buscador de tesoros que sabemos realizó excavaciones clandestinas en La Paloma (Hernández Pacheco 1923a: 8).

\subsection{Cueva de La Lluera I (San Juan de Priorio, Oviedo)}

Las noticias disponibles sobre la presencia de niveles azilienses en la Cueva de La Lluera I están fuera de toda duda (Fortea Pérez 1981: 14; Rodríguez Asensio 1990). De los seis estratos arqueológicos identificados en este yacimiento durante las excavaciones de la primera mitad de la década de 1980, dos niveles (I y II) se definieron como azilienses. Ambos corresponden al tramo final de la secuencia. En un primer momento, el material arqueológico exhumado en el Nivel I fue definido como Magdaleniense 
superior o Aziliense (Rodríguez Asensio 1990: 16), con una fecha de ${ }^{14} \mathrm{C}$ de $10.280 \pm 230$ B. P. (ibidem: 15). Pero el nivel II no dejó lugar a dudas sobre la filiación de ese depósito. Este último fue subdividido en dos tramos por una capa fina de fragmentos de caliza, cada uno de los cuales ofrecía un conjunto ergológico diferente (ibidem: 16-17): según los datos publicados, el subnivel inferior (IIB) correspondería a un Magdaleniense final cantábrico y el superior (IIA) encajaría en las industrias típicamente azilienses.

Entre los materiales más representativos del Nivel I destaca una base de Arpón con ojal. Por su parte, el Nivel IIA se caracteriza por la presencia de raspadores circulares de pequeño tamaño, raspadores nucleiformes y laminillas de dorso doble, así como por un repertorio óseo que, aun manteniendo las características generales observadas para el tramo inferior, muestra diferencias notables con el anterior. En este capítulo se llama la atención sobre un Arpón plano de una hilera de dientes decorado y con posible perforación en ojal. La decoración (dos líneas oblicuas paralelas con incisiones verticales más cortas cubriendo el espacio entre ambas, motivo ejecutado sobre las dos superficies planas) entra de lleno en los rasgos definidos como propios del Aziliense antiguo (FernándezTresguerres Velasco 1990: 92; 1995: 210; 1994: 83; 1997: 195), momento que también se ha caracterizado, desde el punto de vista del repertorio lítico, por la presencia de puntas microlíticas largas y estrechas con doble dorso. El resto de la morfología del Arpón (una hilera de dientes; número impar de estos) entra de lleno en rasgos de los arpones atribuidos al Aziliense clásico (Fernández-Tresguerres Velasco 1995: 214-215; Fernández-Tresguerres Velasco \& Junceda Quintana 1994: 91-93), lo que ha llevado a definir este nivel desde un punto de vista morfotécnico como Aziliense antiguo muy cercano al clásico (Adán Álvarez 1995: 397-404; 1997: 79), algo que estaría en consonancia con la fecha radiocarbónica obtenida para el nivel I, inmediatamente superior.

\subsection{Sofoxó I (Rañeces, Las Regueras)}

Las primeras noticias sobre la atribución aziliense del depósito de Sofoxó I ya planteaban dudas en torno a la posible remoción del depósito y la mezcla de materiales de distinta filiación (Obermaier 1925: 190; Hernández Pacheco 1919: 27; Vega del Sella 1930: 69). Las revisiones modernas de su estratigrafía y materiales arqueológicos tampoco arrojan demasiada luz sobre su cronología. Francisco Jordá (1952: 372; 1963: 16) determinó la presencia de Aziliense, apreciación que más tarde cambia por «varios suelos magdalenenses, ya que los materiales recogidos apun- 
tan también a etapas superiores" (Jordá Cerdá 1976: 102). Los primeros trabajos recientes sobre el registro de la cavidad se inclinaron por encuadrar ésta en el Magdaleniense medio asturiano, advirtiendo la existencia de un nivel Magdaleniense superior destruido parcialmente (Corchón Rodríguez 1971:33). Sin embargo, un trabajo realizado apenas un año después, bajo precisiones geológicas, se inclinó más bien por definir un estrato revuelto compuesto básicamente por elementos del Magdaleniense superior y por algunos componentes del Magdaleniense medio (Corchón Rodríguez \& Hoyos Gómez, 1972/73). Apenas unos años después, otros estudios sugirieron que los restos localizados en la cueva podrían corresponder a un Magdaleniense inferior contaminado con instrumental del tramo superior, advirtiendo de las dudas que plantea una mera distinción tipológica (Utrilla Miranda 1976; 1981: 42-43).

Las primeras sugerencias modernas sobre la presencia de horizontes azilienses en la cueva aparecen en la sistematización seminal del Aziliense de Asturias y Santander, atendiendo a las alusiones clásicas de Obermaier y Hernández Pacheco (Fernández-Tresguerres Velasco 1980: 52). Algunos años después, otros estudios aceptaron estas asunciones, sólo que destacando la posibilidad de que el único estrato en cuestión agrupara dos industrias: un depósito aziliense en el tramo superior y otro del Magdaleniense superior/final en el inferior (González Sáinz 1989: 32). El análisis tecnomorfológico de la colección ósea del yacimiento apunta dos posibilidades (Adán Álvarez 1995: 484-490; 1997: 106-107): bien la mezcla de materiales del Magdaleniense medio y superior, bien su pertenencia al tecnocomplejo del Magdaleniense superior/final con pervivencias tecnológicas de episodios anteriores, sin poder descartarse una datación en el Aziliense antiguo. En este sentido, destaca la presencia de un colmillo trabajado de jabalí, característico de fases finales del Tardiglaciar (Adán Álvarez 1995: 487). En suma, si bien el registro de la Cueva de Sofoxó I se presta a la discusión nos deja abierto un resquicio a la posibilidad de que mantuviera evidencias pertenecientes al Aziliense, siquiera temprano.

\subsection{Cueva Oscura de Perán (Perlora, Carreño)}

La excavación de Cueva Oscura de Perán, realizada en la primera mitad de la década de 1960 (Fernández Rapado \& Mallo Viesca 1965) exhumó, en opinión de sus responsables, un único Nivel aziliense (Capa 2). En una cata de sondeo secundaria, bajo una gruesa capa estalagmítica $(45 \mathrm{~cm}$.) de origen pre-boreal (Laville \& Hoyos Gómez 1981: 
210), existiría un Nivel aziliense, caracterizado por un Arpón con perforación en ojal. Del conjunto lítico recuperado se ha destacado la tendencia al microlitismo de la talla en sílex y la presencia de raspadores sobre extremo de lámina. El Arpón descubierto poseía tres dientes rectos y curvos, así como una perforación en ojal a la altura del último diente, características que permitirían encuadrarlo dentro del Aziliense clásico o reciente (Adán Álvarez 1995: 508-510; Fernández-Tresguerres 1990: 94; 1995: 214-215; Fernández-Tresguerres Velasco \& Junceda Quintana 1994: 91-93). Lawrence G. Straus (1974; 490; 1983: 38-39) cita unas excavaciones realizadas por Francisco Jordá a finales de la década de 1960 (Adán Álvarez en prensa; Jordá Cerdá 1969: 289), cuyos materiales fueron agrupados atendiendo a niveles arbitrarios. Su interés en la cavidad radica en la designación de niveles solutrenses que previamente fueron atribuidos al Magdaleniense medio (Jordá Cerdá 1976: 103).

\subsection{Cueva del Ángel (Santo Adriano, Tuñón)}

La Cueva del Ángel forma parte del complejo cárstico que bordea el río Trubia a la altura de Tuñón, ubicación de numerosas cuevas, y distante aproximadamente un kilómetro de la Cueva del Conde o del Forno (Tuñón, Santo Adriano). Las primeras referencias de la cavidad se deben a Llopis Lladó (1956), quien la denomina Cueva de Tuñón. El grupo aficionado Colectivo de Prehistoria Negro Camargo realizó en 1979 una prospección, recogiendo piezas superficiales. El material lítico se encuentra depositado en el Museo Arqueológico de Asturias (Oviedo). Antonio Juaneda, integrante del Colectivo mantiene en su poder una serie de piezas, entre las que destacan dos Arpones azilienses completos y tres fragmentos de otros, si bien no está claro si su recolección corresponde a la intervención de 1979 o a una visita posterior.

En 1990 se realizó una limpieza de los restos que una pala excavadora sacó a la luz (Adán Álvarez 1995: 309-315; 1997: 55-57; Adán Álvarez \& Jordá Pardo 1992). Dado el carácter de la intervención (solo se excavó una secuencia y una cuadrícula con sedimento residual), resultó difícil distinguir las colecciones líticas y óseas por otro motivo que el puramente estratigráfico. En la secuencia se identificó un nivel claro (N10.2.2.) que por su composición podría pertenecer, a grosso modo, bien al Auriñaciense, bien al Magdaleniense Inferior. La proximidad con la Cueva del Conde podría apuntar hacia el Auriñaciense (Adán Álvarez 1997:57). 
Un segundo nivel (N5) mostraba restos orgánicos, pero solo pudo apreciarse un retazo (columna), y unas pocas piezas poco significativas. Este estrato se localizaba muy próximo a la superficie y no sería extraño que en 1979 se hubiera excavado en él, o que antes de la intervención de 1990, originada por una denuncia, se hubieran encontrado en la ladera materiales árqueológicos como los arpones mencionados.

\subsection{Cueva de la Peña de Candamo (San Román de Candamo)}

Existen también algunas alusiones a piezas azilienses procedentes de la Cueva de la Peña de Candamo, pero un análisis detallado de los datos permite desestimar esta atribución. Soledad Corchón (1986: 473) menciona que, durante una revisión de materiales almacenados en el Museo Arqueológico de Asturias, encontró que un fragmento de costilla decorada con motivo reticulado profundo y carente de referencias estratigráficas (Barandiarán Maestu 1973: 104), se asociaba a un Arpón aziliense. A esto se añade un fragmento redondeado de metápodo con perforación en ojal y decoración angular, considerado en su momento como extremidad proximal de Arpón plano (ibidem: 105), elemento propio de momentos Azilienses. Dada la materia prima y la morfología (presenta sección rectangular) es más plausible que esta pieza sea el extremo proximal de una espátula o puñal (Adán Álvarez 1997: 108).

El Arpón aziliense mencionado por Soledad Corchón no ha sido localizado en revisiones posteriores de los materiales y la decoración del fragmento óseo al que supuestamente acompañaba parece propia de las fases más recientes del Magdaleniense (Corchón Rodríguez 1986). En cuanto al extremo proximal perforado, aunque puede compararse con las diáfisis perforadas azilienses (ibidem: 475 y 478) también se asemeja a un puñal localizado en el Magdaleniense inferior de Cova Rosa (ibidem: 356357), datación más acorde con la supuesta para Peña de Candamo (Solutrense superior con mezcla de materiales propios del Magdaleniense inferior; ibidem: 258) y el tipo de decoración angular que presenta, propia de fases magdalenienses, sobre todo de las más recientes (ibidem: 131). Si a esto sumamos que el análisis morfotecnológico del conjunto óseo procedente de este yacimiento señala la pertenencia del mismo a las fases Solutrense superior/Magdaleniense inferior (Adán Álvarez 1997: 109), hemos de concluir que la Cueva de la Peña de Candamo no puede incluirse en el haber del recuento de indicios Azilienses en la cuenca fluvial del Río Nalón. 


\section{CUEVA OSCURA DE ANIA: YACIMIENTO AZILIENSE EN} LA CUENCA DEL NALÓN

\subsection{Contexto geográfico}

Cueva Oscura de Ania se ubica junto al río Andallón (Lám. 2), en la parroquia de Ania (concejo de las Regueras). Posee dos bocas abiertas hacia el este, sobre la margen izquierda del cauce. Estas entradas dan paso a una sala de dimensiones medias, dividida claramente en dos zonas casi simétricas por obra de una serie de bloques calizos de volumen apreciable, fruto de uno o varios episodios de derrumbe del techo. El cauce del Andallón forma uno de los numerosos valles que descienden sobre la gran arteria fluvial del Nalón, de la que es tributaria en su cuenca media. Cueva Oscura de Ania está situada justamente en la vertiente derecha del curso medio del río Andallón, a unos mil quinientos metros de su desembocadura en el Nalón. Su cota aproximada es de 140 metros sobre el nivel del mar y las altitudes que constituyen las cumbres que rodean el valle en este sector son muy modestas: se sitúan apenas a 280 metros.

El territorio en cuestión constituye una de las áreas de poblamiento paleolítico más intenso de la cuenca media del Nalón. No en vano, Cueva Oscura de Ania está situada a medio camino de las cuevas de La Paloma y Sofoxó (Lám. 2). La primera de ellas se ubica a poco más de tres kilómetros de Cueva Oscura de Ania en línea recta, en el valle colateral del río Soto, en su curso alto. El valle, asimétrico, ofrece alturas máximas en torno a los 280 metros en la vertiente izquierda y los 500 metros en la derecha. Por su parte, Sofoxó se localiza en la confluencia de los ríos Nora y Nalón, a unos dos kilómetros y medio en línea recta desde Cueva Oscura de Ania, y rodeado por alturas modestas que casi en ningún momento superan los 200 metros de cota. Las facilidades de comunicación entre las tres cuevas son evidentes, con La Paloma dominando una pequeña cordal por un collado situado en torno a Santullano (170 metros) y Sofoxó descendiendo hasta el cauce del Nalón. La proximidad entre las tres cuevas y las facilidades de acceso entre sus valles colaterales predisponen a suponer un grado alto de interrelación durante las épocas en que las tres tuvieran ocupación humana.

\subsection{La investigación en Cueva Oscura de Ania}

La existencia de yacimiento prehistórico en los depósitos de Cueva Oscura de Ania era conocida desde 1958 por los alumnos del Instituto de 
Enseñanza Media de Grado (Adán Álvarez 1995: 433; 1997: 85). Sin embargo, la cueva no transcendió a la investigación arqueológica hasta aproximadamente una década después, cuando los restos fueron reconocidos por Manuel Pérez Pérez, a la sazón integrante del Seminario de Prehistoria de la Universidad de Oviedo (Pérez Pérez 1977: 180). Años más tarde, en 1975, el yacimiento fue incluido en el Plan de Excavaciones del mencionado Seminario de Prehistoria. Los trabajos de campo se iniciaron bajo la dirección de José Manuel Gómez Tabanera y Manuel Pérez Pérez (Gómez Tabanera et alii 1975: 61; Pérez Pérez 1977: 180; 1978: 79), prolongándose durante seis campañas, hasta 1980 (Pérez Pérez 1992: 625). Según la propuesta del proyecto de investigación (Gómez Tabanera 1975a), el equipo estaría compuesto por: M. Pérez Pérez (paleolitista); J. Cano (secretario); A. Diego Llaca (grafista); F. J. Villalta (Instituto Jaime Almera de investigaciones geológicas del C.S.I.C, Paleontólogo) y J.M. Quintanal (edafólogo).

Las excavaciones se desarrollaron en las dos zonas que marcan los bloques de caliza en el vestíbulo de la cueva (Lám. 3). En el sector norte

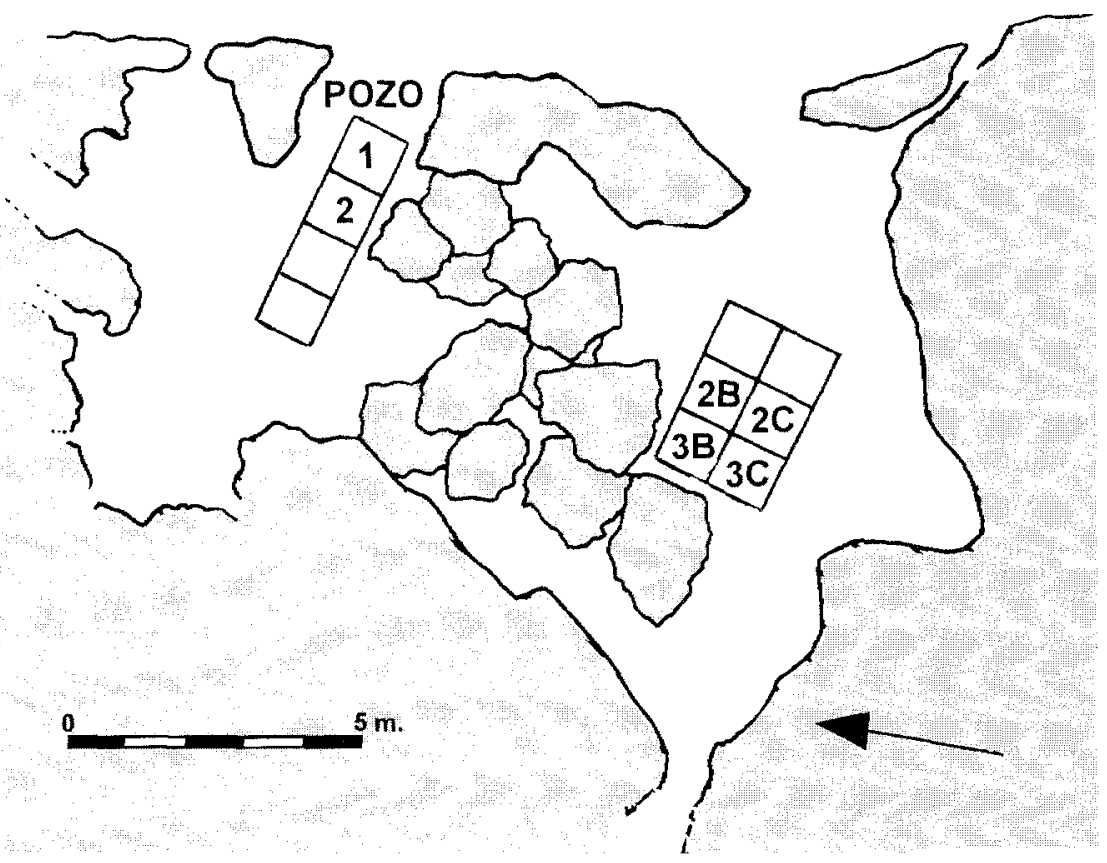

Lám. 3. Plano del vestíbulo de Cueva Oscura de Ania con la situación de las áreas de excavación mencionadas en el texto (según Gómez Tabanera et alii. 1975). 
se realizó una cata de sondeo de $2 \mathrm{~m}^{2}$, encontrando un revuelto causado por un buscador de tesoros en 1934 (Gómez Tabanera et alii 1975: 61; Pérez Pérez 1978: 79). En el área sur se excavaron $4 \mathrm{~m}^{2}$, y a ella parecen corresponder los materiales arqueológicos que hemos revisado.

La presentación de la cueva al ámbito científico puede encontrarse en dos publicaciones genéricas centradas en la primera campaña de excavación, donde se menciona la secuencia estratigráfica básica y una descripción somera de los materiales líticos y óseos, tanto de los dos niveles azilienses como del nivel magdaleniense (Gómez Tabanera et alii 1975; Pérez Pérez 1977). Existen también algunas notas sobre piezas concretas de su registro (Pérez Pérez 1977, 1978, 1992) y una valoración preliminar de algunos restos de pintura sobre las paredes de la cueva, que fueron interpretados como "figura de bisonte" (Cano Díaz 1977; Gómez Tabanera et alii 1975), aunque todo parece apuntar a que se trata de una mancha de color carente de interés artístico (Adán Álvarez 1995: 433). Apenas algunas citas aisladas, someras menciones de piezas singulares (Gómez Tabanera 1980: 69, 117 y 178), completan este parco panorama.

\section{CUEVA OSCURA DE ANIA: PLANTEAMIENTO ESTRATIGRÁFICO}

Como ya se ha expresado, las únicas referencias sobre la secuencia estratigráfica de Cueva Oscura aparecen en dos publicaciones de mediados de la década de 1970 ya mencionadas, presentación sumaria de los resultados proporcionados por la primera campaña de excavación (Gómez Tabanera et alii 1975; Pérez Pérez 1977). Esta secuencia ha pasado a la literatura arqueológica como fruto exclusivo de los trabajos de campo realizados en el sector sur de la cavidad por Gómez Tabanera y Pérez Pérez (Adán Álvarez 1995: 434-435, 1997: 85; Corchón Rodríguez 1986: 30-31; Fernández-Tresguerres Velasco 1980: 49-50). Sin embargo, parece que tanto el planteamiento de la excavación como las conclusiones preliminares estuvieron bastante influenciados por las observaciones realizadas durante la limpieza del sector norte del vestíbulo (Pérez Pérez 1978: 79), zona revuelta por un buscador de tesoros que hacia 1934 abrió sendas catas de furtivo frente a ambas bocas de la cueva. Con posterioridad, durante la Guerra Civil española (1936-1939), ese mismo sector norte fue utilizado por los habitantes de los alrededores como escondrijo ocasional de armas y objetos de valor (Gómez Tabanera et alii 1975: 61).

En cualquier caso, los estudios parciales disponibles hasta este momento no hacen referencias concretas y detalladas al contexto general o la 
sedimentología de la secuencia, al parecer en estudio en las fechas de publicación de la misma (Pérez Pérez 1977: 184). Ni siquiera en los dibujos de los cortes estratigráficos de los artículos publicados por sus excavadores se hace referencia a los niveles identificados (Lám. 4). Todo parece indicar que en la distinción de niveles intervinieron de manera singular las diferencias observadas en el contenido ergológico. Se enumeran los siguientes niveles, de techo a base:

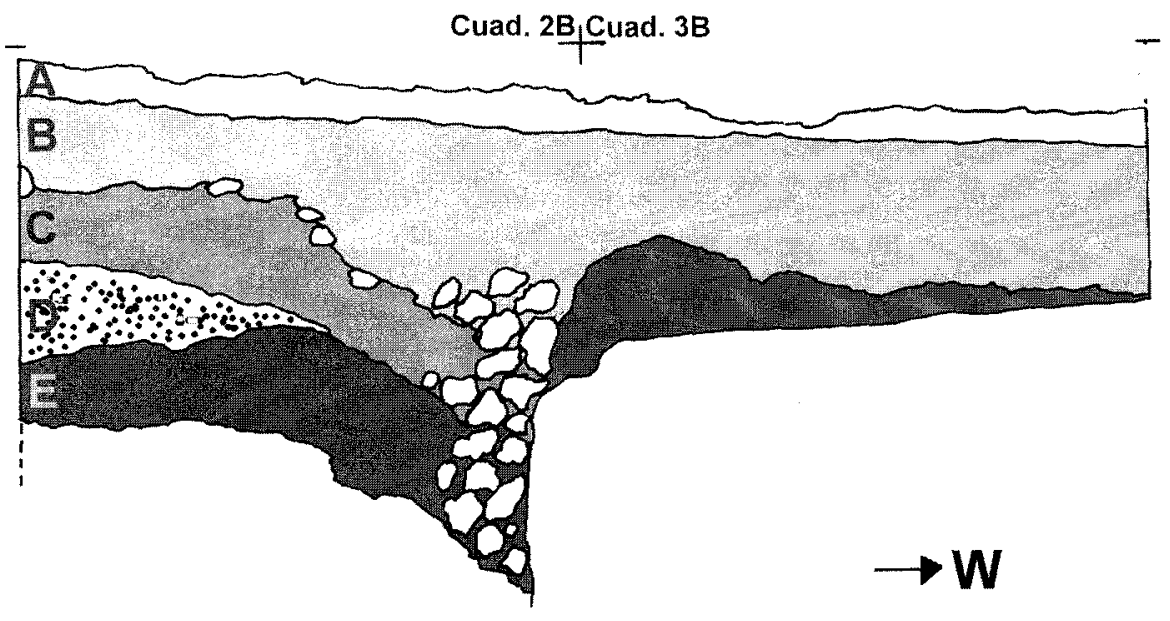

Lám. 4. Perfil estratigráfico (norte) del área de excavación sur de Cueva Oscura de Ania (según Gómez Tabanera et alii 1975: 62, fig. 2). En ausencia de datos de primera mano que aclaren la situación, la correspondencia con los niveles definidos en las noticias del yacimiento publicadas hasta la fecha plantea serias dudas y nuestra propuesta debe entenderse como una reconstrucción hipotética a contrastar. ¿ $A=$ Nivel superficial; $B=N i v e l$ 1/Horizontes o y Oa; $C=N i v e l 2 /$ Horizontes ob y $O c ; D=N i v e l$ de arcillas blancas; $E=N i v e / 3$ ?

a) Nivel superficial. Las informaciones disponibles no ofrecen ningún tipo de comentario sobre el espesor, distribución y características de este nivel. Tan sólo se dice que la superficie se encontraba muy revuelta (Gómez Tabanera et alii 1975: 61; Pérez Pérez 1977: 184). Sin embargo, durante nuestra revisión de los materiales conservados en el Museo Arqueológico de Oviedo apenas hemos encontrado piezas atribuidas a este nivel. Estas se reducen a in puñado de cerámicas sin cota conocida.

b) Nivel 1: "Aziliense Cantábrico". Las primeras publicaciones no revelan las características sedimentológicas del nivel (Gómez Tabanera 1975b; Gómez Tabanera et alii 1975), aunque un trabajo posterior comenta sucintamente que durante su excavación se diferenciaron dos subniveles (Pérez 
Pérez 1977: 184), sin explicar las razones de esta división ni si se apreciaron discrepancias entre los contenidos de ambos. Según sus excavadores, la industria lítica de este Nivel 1 ofrece como características esenciales: un porcentaje alto de "disquitos raspadores" y de laminillas de dorso; una presencia de buriles sensiblemente inferior a la de raspadores; una tendencia microlítica de los raspadores y una "factura descuidada» de los buriles. Se incide sobre la abundancia de utillaje tallado en cuarcita así como los «rasgos musteroides» de un gran número de piezas en este lecho. En cuanto a la industria ósea, se comenta la ausencia de Azagayas y la presencia de un metatarso apuntado de cáprido, clasificado como puñal, y de un fragmento de Arpón plano. La atribución industrial de este nivel es clara en el texto: «... denominamos «Aziliense típicamente Cantábrico» a aquella industria, no bien definida aún en todos sus aspectos, que se manifiesta en toda la cornisa y que presentando características de Mas d'Azil parece evolucionar directamente del Magdaleniense final Cantábrico" (Pérez Pérez 1977: 184, nota 5).

c) Nivel 2: “Aziliense atípico». Los parcos comentarios estratigráficos sobre este segundo nivel aziliense no dudan en reseñar la notable complejidad de esta capa (Gómez Tabanera et alii 1975: 63; Pérez Pérez 1977: 187), aunque no se ofrece ninguna información complementaria que aclare este relevante aspecto. El material recuperado se caracteriza por la presencia de raspadores pequeños, un porcentaje aún más alto de laminillas de dorso, un descenso del índice de buriles y la presencia de puntas «estrechas y simétricas» de doble dorso. En comparación con el nivel aziliense anterior, los autores destacan la ausencia de materiales "musteroides" $y$ el descenso de utillaje fabricado en cuarcita. En cuanto a la industria ósea y el arte mueble, se reseña la presencia de dos arpones planos de una hilera de dientes sin perforación basal y tres cantos supuestamente pintados (Gómez Tabanera et alii 1975: 63; Pérez Pérez 1977: 187 y 191). La atribución de este nivel a periodos Azilienses, si bien poco estandarizado 0 atípico, se fundamenta precisarnente en estas piezas singulares: «(...) trois caillaux avec des marques de peinture, ce qui avec les harpons signalés plus haut, semble souliger le caractère azilien de ce niveau, bien qu'avec des caractéristiques très particulières" (Gómez Tabanera et alii 1975: 63); “El hallazgo de tres cantos pintados, unido al de los arpones antes comentados, corrobora el carácter aziliense de este nivel, pero con características muy particulares" (Pérez Pérez 1977: 191). En lo tocante a los especímenes definidos como cantos pintados, queremos hacer notar que su estudio detenido permite desechar que puedan calificarse como tales. En realidad se trata de dos percutores de arenisca y un posible compresor de cuarcita con impregnaciones de ocre y colorante negro. Éstas, 
lejos de manifestar intencionalidad artística alguna, parecen fruto de haber utilizado estos objetos para machacar y extender los pigmentos. Es de destacar que para este nivel contamos con dos fechas de ${ }^{14} \mathrm{C}$ publicadas: 11.880 \pm 200 B. P. y $9.440 \pm 90$ B. P. (Pérez Pérez 1992: 642, nota 16).

d) Nivel de arcilla blanca.

e) Nivel 3: «Magdaleniense superior Cantábrico». En uno de los trabajos más recientes sobre la cueva (Pérez Pérez 1992 : 641, nota 15) se señalan las características sedimentológicas del nivel, basadas en los diarios de excavación. Se trata de un depósito variable, que evoluciona progresivamente desde unas tierras amarillentas con numerosos y abundantes «restos termoclásticos" (en la base) hasta unas tierras más oscuras, más sueltas, con una granulometría más fina y una menor presencia de crioclastos hacia el techo. Se reseña una presencia de buriles más acusada que en los niveles superiores, señalándose una factura más cuidada para los mismos. Al mismo tiempo, entre los raspadores no se aprecia la presencia de tipos circulares y se llama la atención sobre la generalización de piezas de tamaño considerable talladas en cuarcita (Pérez Pérez 1977).

\section{CUEVA OSCURA DE ANIA: INDUSTRIAS LITTICA Y ÓSEA AZILIENSES}

El conjunto lítico aziliense procedente de las excavaciones en Cueva Oscura de Ania comprende más de 1.200 piezas consideradas como útiles, número que nos habla de una colección amplia y representativa. Por el contrario, el registro óseo seleccionado se compone tan sólo de 85 piezas, que fueron consideradas como Industria Ósea, en las excavaciones dirigidas por Gómez Tabanera (campañas de 1975 y 1976). Algunos de estos especímenes, entrarían de lleno en lo que nosotros hemos considerado como "Restos con marcas de carnicería" (Adán Álvarez 1997: 18 y 37-40), mientras otras son claramente «Piezas trabajadas», en las que se incluye los fragmentos de matriz, las piezas en fabricación y los morfotipos indicativos. (ibidem: 18, 21-22 y 40-47). Algunos de estos ejemplares ya habían sido publicados en el avance de la excavación de 1975 (Gómez Tabanera et alii 1975: 64).

El estado actual de nuestra investigación no permite avanzar mucho más allá de una caracterización de sus repertorios y algunas propuestas cronológicas. En el caso de la industria lítica, aún queda bastante por hacer, como un estudio detenido de la variabilidad de materias primas. La primera impresión que se desprende es que pudo existir cierta selección 
de la misma en función del utillaje a fabricar. Esto es, para la realización de algunos tipos se prefieren determinadas variedades de piedra. Por otra parte, llama poderosamente la atención la cantidad de especímenes que presentan alteraciones térmicas en toda la secuencia aziliense del yacimiento. De momento, nada podemos decir sobre la dispersión de los mismos o si ésta pudiera poner en evidencia estructuras latentes, como hogares. Esta son algunas de las líneas a seguir por nuestro trabajo futuro.

En cualquier caso, se hace necesario recalcar en el hecho de que en este artículo presentamos resultados preliminares y las conclusiones extraídas a partir de ellos pueden estar sujetas a matizaciones y modificaciones conforme avancemos en el estudio del yacimiento y su registro.

\subsection{Problemática}

Las referencias de las etiquetas de las cajas y bolsas que contienen los materiales procedentes de los niveles azilienses de Cueva Oscura de Ania depositados en el Museo Arqueológico de Asturias no reflejan una denominación concordante con la estratigrafía publicada (Niveles 1 y 2). El registro aziliense está catalogado como perteneciente a un «Nivel 0» subdividido en cuatro horizontes (0, $0 a$, Ob y $0 c)$. En ausencia de documentación o testimonios que pudieran aclarar la situación, estas sensibles diferencias entre la nomenclatura de etiquetado y la de publicación, así como la ausencia de cotas en un considerable número de etiquetas, ocasionan no pocas dificultades a la hora de encontrar una correspondencia. El panorama se ve complicado por dos factores. El primero de los mismos es que se constatan menciones a un nivel superficial (Gómez Tabanera et alii 1975: 61; Pérez Pérez 1977: 184) pero los materiales referenciados al mismo son inexistentes, si exceptuamos un puñado de fragmentos cerámicos siglados como correspondientes a un "Horizonte 0/Superficial». El segundo factor a tener en cuenta es la ausencia en el almacén del Museo de especímenes procedentes del sector septentrional del yacimiento. Es posible que cuatro piezas líticas y algún fragmento óseo consignados como pertenecientes a un Cuadro IV puedan adscribirse a esta zona, pero en la actualidad nada podemos afirmar al respecto. Por otra parte, según las indicaciones de las bolsas que contenían los materiales óseos, la campaña de 1975 se centró en los cuadros $2 b$ y $2 c$, y se diferenciaron los horizontes que se designaron como 0a (cotas en el cuadro $2 \mathrm{~b}$ : de -23 a $-40 \mathrm{~cm}$., y en el $2 \mathrm{c}$ : de $-32 \mathrm{a}-36 \mathrm{~cm}$.) y Ob (sin cotas en ninguno de los dos cuadros, tanto en los materiales líticos como óseos). En la superficie se recogieron piezas cerámicas (cuadros 2c y 3c). Durante 
1976, se excavaron los cuadros $1 \mathrm{~b}$ y $1 \mathrm{c}$, en los que se detectaron los Horizontes 0a (cotas en el cuadro 1b: de $-30 \mathrm{~cm}$., y en el 1c: de -27 a -30 $\mathrm{cm}$.), Ob (sin cotas) y Oc (sólo aparece en el 1c: de -52 a $-57 \mathrm{~cm}$.) ${ }^{1}$.

Nuestro estudio preliminar de dispersión de materiales, realizado a partir de las coordenadas proporcionadas por los excavadores del yacimiento en sus etiquetas, tampoco han arrojado demasiado luz sobre esta cuestión. Los materiales más característicos del Nivel 2 citados en la bibliografía relativa a la Cueva (Gómez Tabanera et alii 1975: 63; Pérez Pérez 1977: 187 y 191), concretamente un fragmento de Arpón plano decorado, dos Arpones planos sin perforación y tres Cantos con pigmentación, nos han inclinado ha considerar que los Horizontes $0 b$ y $0 \mathrm{c}$ dan forma al denominado Nivel 2. Por eliminación, puesto que contamos con una alusión a la diferenciación de dos subniveles durante la excavación del nivel 1 (Pérez Pérez 1977: 187), lo lógico es suponer que éstos corresponderían a los Horizontes 0 y 0 a. Cuando menos, esa ha sido la opción que hemos tomado. Se hace necesario validar nuestras deducciones contrastándolas sobre el terreno y con la información al respecto que a buen seguro encontraríamos en los diarios e informes de excavación.

Para añadir aún más confusión a esta situación, los materiales correspondientes al Horizonte 0 a se concentran en un sector que, a grosso modo, se corresponde con un vacío en la dispersión del Horizonte 0 y fue excavado en una campaña diferente. Una explicación plausible pudiera ser que durante el proceso de excavación del Nivel 1 se interpretara este sector como «hogar». Esta suposición viene avalada por el detalle de que algunas piezas del Horizonte 0 a aparecen sigladas como «0a-H». En cualquier caso, la observación de la representación gráfica de perfiles estratigráficos publicada para Cueva Oscura de Ania (Gómez Tabanera et alii 1975: 62; Pérez Pérez 1977: 183) nada permite aclarar al respecto. De nuevo se hace evidente que, dado el estado actual de nuestra revisión, no podemos avanzar más allá en este aspecto.

\subsection{Horizonte 0}

\subsubsection{Conjunto lítico (Lám. 5)}

Este horizonte aziliense, el más próximo a la superficie del yacimiento, es el que cuenta con una mayor proporción de piezas líticas catalogadas:

\footnotetext{
1 Por lo tanto, falta en este cuadro $1 \mathrm{c}$, un tramo desde el final del $0 \mathrm{a}(-30 \mathrm{~cm}$.), hasta el inicio de Oc $(-52 \mathrm{~cm}$.$) , ¿será un nivel estéril, o parte del ob sin restos óseos?$
} 
prácticamente la tercera parte de los materiales inventariados como útiles pertenecen a esta unidad (en torno a 370 piezas). En grandes líneas, los raspadores constituyen el grupo tipológico dominante, seguido por el instrumental microlaminar, buriles y tipos de substrato (denticulados, escotaduras y raederas). A continuación se detallan las características singulares de cada uno de estos grupos:

a) Raspadores. Los raspadores constituyen el grupo tipológico dominante, concentrando casi una tercera parte del total de los materiales líticos catalogados (más concretamente, un $30 \%$ ). La mitad de los raspadores pertenecen a las variedades en extremo de lasca y lámina, cuyos soportes aparecen en buena parte acortados por procesos de fractura proximal. Bien es cierto que también existe una notable representación de los tipos altos y sobre lascas de tamaño apreciable (que suponen hasta el $36 \%$ de este grupo). Por lo demás, merece la pena destacar la presencia de los típicos raspadores microlíticos «tipo botón» (representan en torno al $13 \%$ del total de este grupo).

b) Utillaje microlaminar. Este espectro constituye el segundo componente tipológico del registro lítico en el Horizonte 0 . Representa poco más de la cuarta parte de la totalidad de los materiales consignados $(26 \%)$. En líneas generales, se trata de un conjunto netamente especializado, pues más de las dos terceras partes de estos útiles resultan ser diversos tipos de laminillas de dorso (en torno al $70 \%$ ). Esta concentración deja en segundo plano otros elementos, de tal manera que tan sólo se han detectado escasas puntas azilienses y microgravettes (en ambos casos representan en torno al $11 \%$ ), así como algunas residuales laminillas de doble dorso (apenas un $2 \%$ ). No se documentan puntas de doble dorso.

c) Otros grupos. Los buriles se acercan al 17\% del total. En cuanto a los tipos de substrato, como denticulados (casi un 4,5\%), escotaduras, raederas y piezas astilladas ( $2,8 \%$ respectivamente), representan en torno al $13 \%$ del total.

\subsubsection{Conjunto óseo}

De las 41 piezas óseas seleccionadas por los excavadores, 21 corresponden a restos de carnicería. Los materiales trabajados de este horizonte incluyen dos restos de cuerna, utilizados para extraer esquirlas (una quemada), y tres diáfisis con huellas de trabajo industrial. Hemos documentado 4 piezas apuntadas. La primera de ellas es un fragmento distal de arpón, realizado sobre cuerna, con una sección oval (publicado en Gómez- 

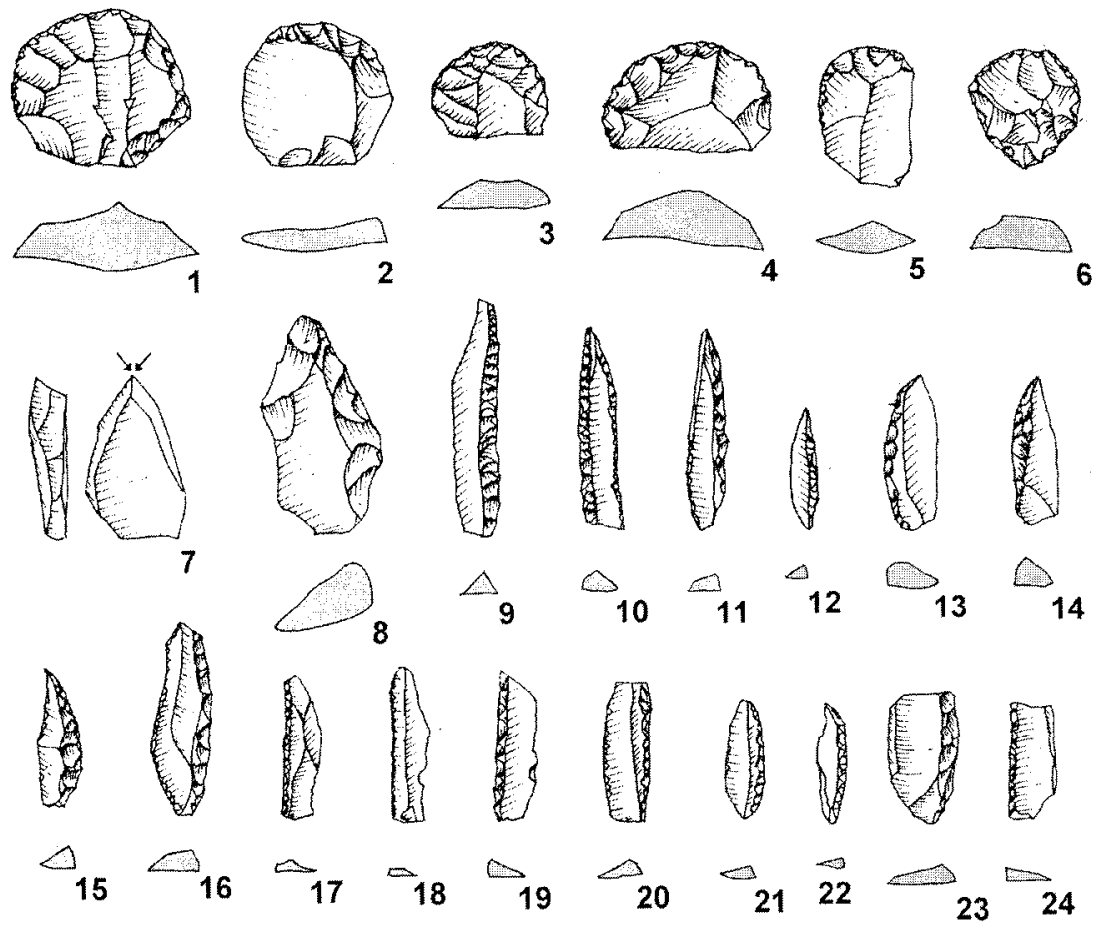

22
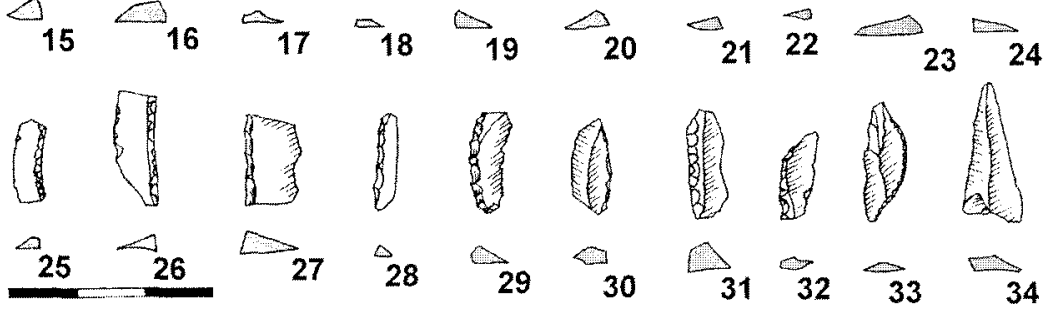

Lám. 5. Muestra de materiales líticos del Horizonte 0. 1-2, 5: Raspadores simples; 3-4: Raspadores sobre lasca; 6: Raspador circular; 7: Buril diedro recto; 8: Punta del chatelperron atipica; 9: Lámina de borde abatido total; 10-12: Microgravettes; 13-15: Puntas azilienses; 16-32: Laminillas de dorso; 33: Segmento de círculo; 34: Triángulo.

Tabanera et alii 1975: 64. Fig. 6), dientes de morfología ganchuda -conformados mediante aserramiento y pulimento- y una punta quemada para conseguir su endurecimiento. La segunda pieza es el fragmento mesial de una azagaya decorada sobre cuerna, con una sección circular y un trabajo intenso mediante aserramiento y pulimento. La tercera es un puñal sobre metatarso de cáprido (también publicado en Gómez-Tabanera et alii 1975: 64. Fig. 4; Fernández-Tresguerres Velasco 1980: 45), con incisiones y golpes producto de la división longitudinal de la pieza y una posterior regulari- 
zación. La pieza se puede comparar con la espátula decorada de los Azules (Adán Álvarez 1997: 85) aún con algunas diferencias morfológicas en el extremo distal. El último ejemplar apuntado es una pieza en proceso de fabricación sobre cuerna, posiblemente para realizar un anzuelo y/o alfiler $(41 \times 5 \times 4 \mathrm{~mm}$.), mediante un apuntamiento lateral.

También hemos reconocido hasta 5 piezas biseladas: 4 alisadores, realizados siempre sobre costillas largas y con presencia de marcas de uso (desgaste) en los laterales y cara inferior; y 1 cuchillo realizado sobre colmillo de jabalí - una pieza muy común en los periodos finales del Tardiglaciar (Adán Álvarez 1997: 343) - con marcas de su separación y esquirlado en la parte externa más cortante. Además hemos podido constatar dos piezas romas: un tensor sobre una diáfisis gruesa $(68 \times 12 \times 11$ $\mathrm{mm}$.), si nos atenemos a las marcas de uso - morfotipo presente durante todo el Tardiglaciar (Adán Álvarez 1997: 346)-; y un proximal romo sobre asta, quemado y fracturado $(18 \times 14 \times 6 \mathrm{~mm}$.), muy regularizado por aserramiento y pulimento, con una tipología bastante difícil de discernir. La colección contiene tres colgantes realizados sobre Trivia europea, con dos orificios pequeños emplazados a ambos extremos.

La mayor parte de las piezas trabajadas fueron realizadas sobre cuerna (9); en menor medida sobre costillas (4) y malacofauna (3); y esporádicamente sobre metatarso de cáprido (1), colmillo de jabalí (1) y diáfisis (1). La principal técnica de trabajo es el aserramiento/pulimento. Las piezas más elaboradas son las apuntadas pues transforman casi toda la pieza matriz; pero el resto no altera sustancialmente la pieza originaria en hueso, a saber: los alisadores sobre costillas, la diáfisis del tensor o los colgantes sobre malacofauna. Debemos resaltar que la forma de trocear el colmillo de jabalí es muy común a finales del Tardiglaciar (Adán Álvarez 1997: 343). Así como los orificios de trivia se obtuvieron por la punción de un útil fino (media $2 \times 2 \mathrm{~mm}$.). Algunas piezas aparecen quemadas: en dos de ellas probablemente como medio para trocear la cuerna; en la otra, el arpón, como forma de endurecimiento; y en la cuarta, un colgante, posiblemente como resultado de su exposición fortuita al fuego.

\subsection{Horizonte $\mathrm{Oa}$}

\subsubsection{Conjunto lítico (Lám. 6)}

El Horizonte conocido como $0 a$ ha ofrecido la muestra aziliense más reducida. La proporción de piezas apenas alcanza el $13 \%$ de la totalidad del material documentado (unos 160 especímenes). La estructura compo- 

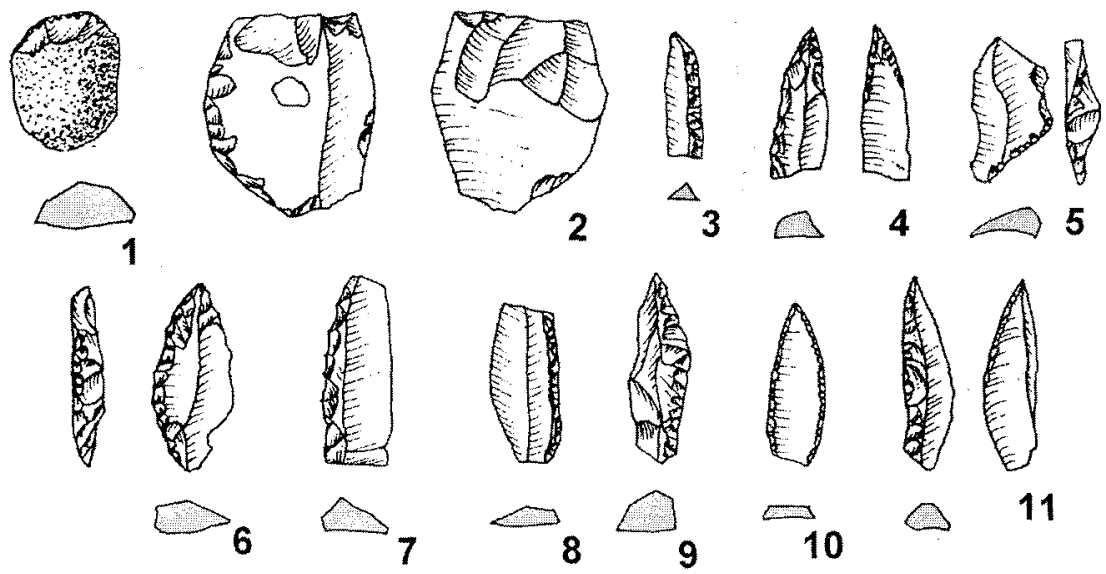

${ }_{10}$

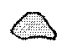

11

Lám. 6. Muestra de materiales líticos del Horizonte 0a. 1: Raspador atípico; 2: Pieza astillada; 3, 7-8: Laminilla de dorso; 4: Microraspador; 5: Triángulo; 6: Segmento de círculo; 9: Punta aziliense; 10: Punta de doble dorso; 11: «Flechette».

sitiva básica del registro lítico es similar a la observada en la muestra del horizonte anterior: los raspadores de nuevo constituyen el grupo tipológico dominante, seguido del utillaje microlaminar y, en tercer lugar, de buriles y tipos de substrato.

a) Raspadores. Tal como sucedía en el horizonte precedente, los raspadores dominan notoriamente el conjunto lítico, incluso en una proporción ligeramente superior: no en vano este grupo concentra en torno a una tercera parte de la muestra catalogada (cerca del $34 \%$ de la totalidad de los materiales consignados como útiles). La mayoría de todas estas piezas corresponden a tipos sobre extremo de lasca y lámina $(41 \%)$, cuyos soportes también aparecen en numerosas ocasiones acortados por fractura proximal. Aunque en menor cantidad, también aparecen raspadores altos y en soportes de tamaño considerable (representan un $36 \%$ aproximadamente). También aparecen raspadores tradicionalmente clasificados como «tipo botón» o microlíticos (representan en torno al $20 \%$ ).

b) Utillaje microlaminar. De la misma manera que en el primer horizonte descrito, el variado utillaje microlaminar constituye el segundo 
componente tipológico de la muestra. Su número supera la cuarta parte de la totalidad de los materiales catalogados (en torno al $29 \%$ ), una proporción ligeramente superior a la observada en la muestra precedente. El conjunto microlaminar está algo menos especializado que en aquella otra, si bien el componente básico vuelven a ser las hojitas de dorso, que acaparan poco menos de las dos terceras partes de este grupo (en torno al $60 \%$ ). Destaca de modo especial la elevada proporción de las laminillas de doble dorso (que representan un $20 \%$ ), en claro contraste con su escasa presencia en el horizonte anterior. Entre las piezas microlaminares menos representadas encontramos las microgravettes y puntas azilienses (en ambos casos se sitúan en torno al $8.5 \%$ ), así como algunas puntas de doble dorso (aproximadamente un $4 \%$ ).

c) Otros grupos. Los buriles agrupan un $13 \%$ del total, mientras que los tipos de substrato representan en torno al 16\%: denticulados (casi un $5,7 \%$ ), escotaduras $(5 \%)$, raederas $(1,9 \%)$ y piezas astilladas (3\% aproximadamente).

\subsubsection{Conjunto óseo (Lám. 7)}

El conjunto óseo seleccionado correspondiente al Horizonte 0a está constituido por 18 restos, entre los que aparecen huesos con marcas de carnicería (5) y piezas trabajadas (13). Los fragmentos con marcas de carnicería son mayoritariamente de descarnación (4), que también han sufrido un proceso térmico (quemado). Únicamente una mandíbula de cáprido muestra huellas de desarticulación. Conviene destacar la presencia de punciones marcadas sobre uno de los huesos, que podrían estar indicando la convivencia de algún carnívoro pequeño con la comunidad antrópica.

Los huesos trabajados reconocidos fueron 3 posibles restos de matrices de asta (distum de candiles quemados con huellas de aserramiento), 1 fragmento de esquirla de cuerna quemada obtenida por ranurado, 6 piezas apuntadas, 1 biselada y 2 colgantes de malacofauna. Todas las piezas han sido tratadas después de su limpieza, con algún consolidante, y una de ellas muestra huellas de roedor (mesial de posible biapuntado).

Como se comprueba destacan por su número, las piezas apuntadas, circunstancia que acontece en la mayor parte de los recuentos óseos. En este grupo aparecen un mesial que hemos considerado de un apuntado (¿biapuntado?) realizado sobre cuerna; un posible fragmento de biapuntado sobre cuerna quemada; otro biapuntado fragmentado en dos; un punzón (Lám. 7, fig. 1) obtenido sobre una diáfisis con huellas de percusión en uno de sus laterales, usado en su extremidad distal (pulimento); y otro punzón 


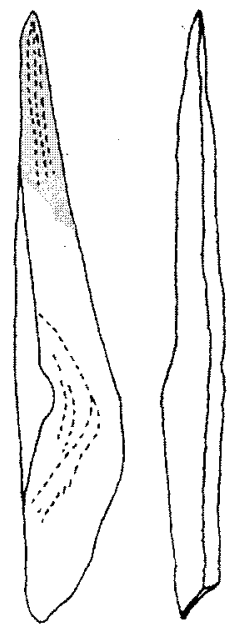

1
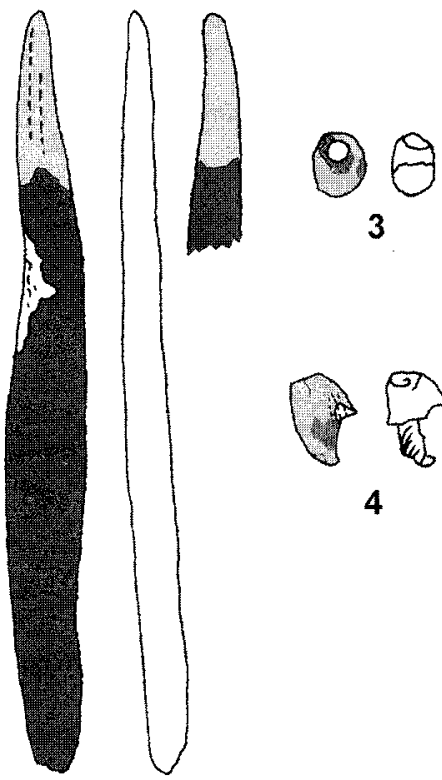

3

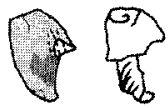

4

2
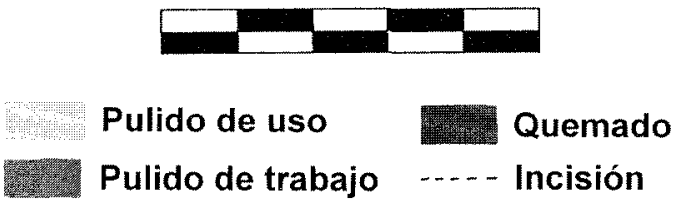

Lám. 7. Muestra de materiales óseos (dibujo técnico) del Horizonte 0a. 1-2: Punzones; 3-4: Colgantes sobre Trivia europea.

(Lám. 7, fig. 2) de esquirla de hueso, quemado, y con huellas de uso (brillo) en la punta. El útil biselado, es un cincel realizado sobre un candil de ciervo con estrangulamiento central y bisel para enmangue, que porta marcas de empleo tanto en su extremidad distal (pulido) como en la proximal (pulido). Cierran esta colección dos colgantes sobre Trivia europea, uno entero (Lám. 7, fig. 3) con perforación mediante presión en la cara superior (3×3 $\mathrm{mm}$.) y otro fragmentado (Lám. 7, fig. 4), horadado en el lateral.

La mayor parte de estos morfo-tipos fueron realizados sobre cuerna de ciervo (9), obteniéndose los restantes sobre diáfisis (2) y malacofauna (2). Es de destacar la gran cantidad de piezas quemadas (7 de 13), algunas coincidiendo con un hogar, como señalan las etiquetas. Llama la atención que se 
sigan obteniendo esquirlas de cuerna mediante ranurado, cuando en esta época de finales del Tardiglaciar, parece que ya no se necesitan varillas tan largas para conformar las piezas óseas (pieza de $87 \times 14 \times 10 \mathrm{~mm}$.). La técnica de transformación más utilizada es el aserramiento/pulimento (5 de 9), mientras las partes apuntadas se consiguen por diversos medios: un punzón por incisiones longitudinales y el otro por incisiones sobre un lateral; los biapuntados por esta última técnica. Las perforaciones se realizan con el empleo de un útil fino (orificio de $3 \times 3 \mathrm{~mm}$.) que presiona la pieza de malacofauna.

Ya hemos explicado como aparecen huellas de uso sobre los punzones (brillo en parte interior de los apuntamientos), y en el cincel (zona pulida interna de casi $35 \mathrm{~mm}$., y de enmangue de unos $36 \mathrm{~mm}$.).

\subsection{Horizonte $O b$}

\subsubsection{Conjunto lítico (Lám. 8)}

El Horizonte ob contiene una cuarta parte de la totalidad de piezas consignadas; aproximadamente un $26 \%$ (poco menos de 300 especímenes).

a) Raspadores. El grupo de raspadores constituye el segundo componente tipológico del registro lítico (suponen poco más del $30 \%$ del total). Casi la mitad de los raspadores pertenecen a tipos sobre extremo de lascas y lámina (en torno a un $46 \%$ ), presentándose de nuevo en muchos casos acortados por fracturas proximales. Tras ellos se han encontrado casi por igual raspadores microlíticos de tipo "botón" y raspadores altos o sobre soportes de tamaño apreciable (suponen un $30 \%$ y $28 \%$ respectivamente).

b) Utillaje microlaminar. A diferencia de los dos primeros horizontes descritos, el utillaje microlaminar constituye en esta ocasión el componente dominante del registro lítico. La proporción de estos tipos es sensiblemente más alta a la demostrada en los tramos superiores de la secuencia y rebasa con creces la tercera parte de la totalidad de las piezas descritas como útiles (en torno al $44,5 \%$ del utillaje). El conjunto microlaminar está algo menos especializado que en cualquiera de las restantes muestras azilienses del yacimiento, si bien el tipo dominante continúan siendo las hojitas de dorso. Estos tipos vienen a representar aproximadamente la mitad del utillaje microlaminar catalogado (su proporción alcanza un 45\%). Destacan de modo especial las elevadas frecuencias de microgravettes, que se sitúan en torno a un tercio de las piezas microlaminares (justamente un 33\%). La colección contiene, además, algunas puntas de doble dorso (suponen aproximadamente el 10\%), laminillas de doble dorso (poco menos del $7 \%$ ) y escasas puntas azilienses (algo más del $3 \%$ ). 

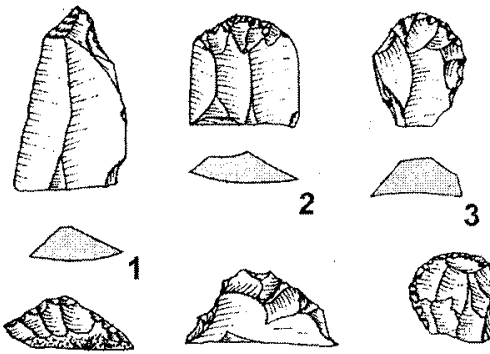

3
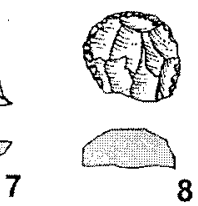

6
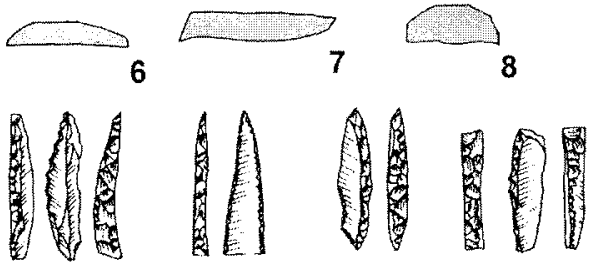

$\triangle 10$

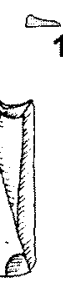

18
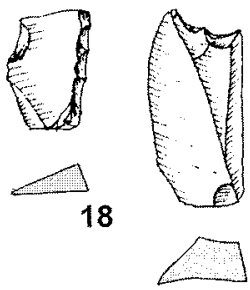

19
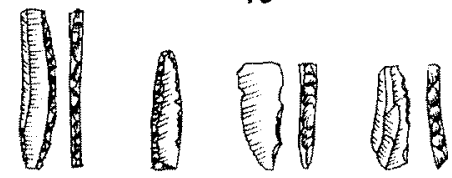

$\triangle_{23} \Delta_{24} \otimes_{25}$

20

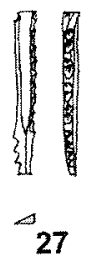

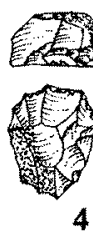
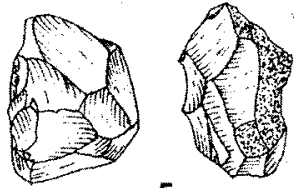

5
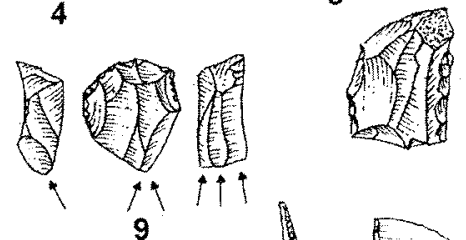

9
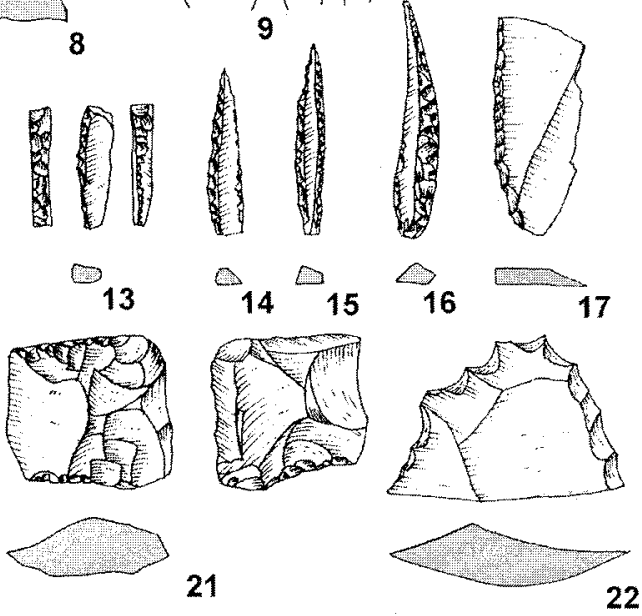

21

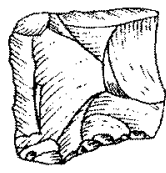

22
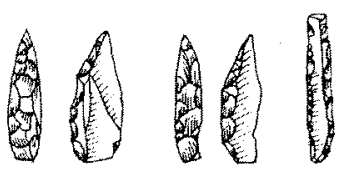

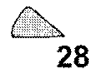

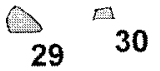

Lám. 8. Muestra de materiales líticos del Horizonte Ob. 1-2: Raspadores simples; 3, 8: Raspadores sobre lasca; 4-5: Raspadores carenados; 6-7: Raspadores atípicos; 9:

Raspador-buril; 10-16: Microgravettes, 17-18: Láminas con dorso abatido total; 19:

Truncadura cóncava; 20: Lámina con retoque contínuo en un borde, 21: Pieza astillada; 22:

Denticulados; 23-26: Láminillas de dorso; 27: Laminilla de dorso denticulada; 28-29: Puntas azilienses; 30: Laminilla de dorso doble. 
c) Otros grupos. Los buriles se sitúan en torno al $18 \%$ del total de la colección. Denticulados (1\%), escotaduras y raederas (alrededor del 1,8\% cada tipo) y piezas astilladas (poco más del $2 \%$ ) no llegan a representar el $7 \%$ del total.

\subsubsection{Conjunto óseo (Lám. 9)}

De los 19 huesos seleccionados para el Horizonce 0b, 6 se incluirían en los restos con marcas de carnicería y 13 en las piezas trabajadas.
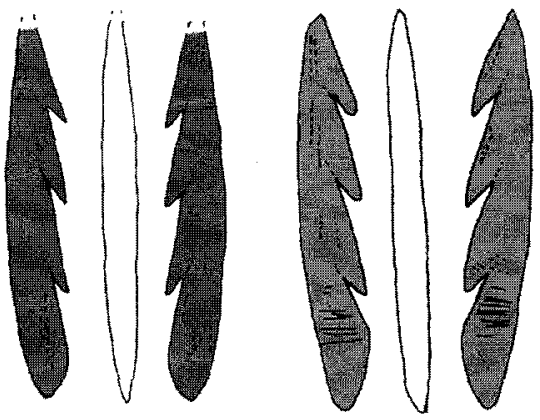

1
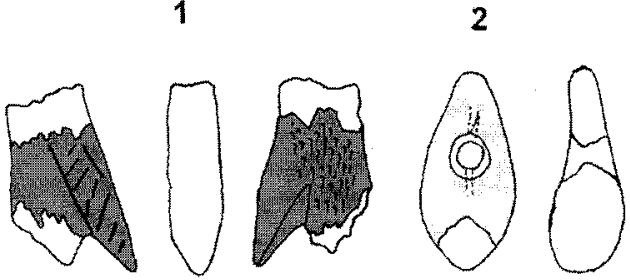

3

4
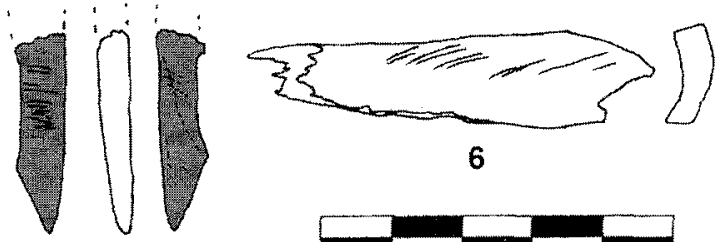

5

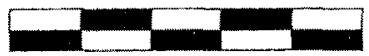

Tafonomía

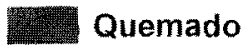

Pulido de trabajo

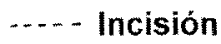

Lám. 9. Muestra de materiales óseos (dibujo técnico) del Horizonte 0b. 1-2: Arpones; 3: Fragmento mesial de Arpón decorado; 4: Colgante; Fragmento proximal de arpón; 5:

Fragmento de hueso con decoración pareada. 
Como en el nivel anterior, las piezas fueron tratadas después de limpiarlas, y solo hemos distinguido dos huesos con marcas tafonómicas (concreciones en una esquirla de cuerna, y sobre un Colgante; Lám. 9, fig. 4).

Los restos óseos de carnicería son 4 diáfisis ( 3 de ellas quemadas), una es una costilla, con marcas de descarnado; 1 mandíbula de jabalí con señales de descarnación; y una lasca obtenida por la presión sobre un hueso largo para extraer la grasa medular.

En cuanto a las 13 piezas trabajadas, distinguimos en primer lugar, 4 fragmentos de matriz de cuerna de ciervo (2 distum quemadas). El grupo de morfo-tipos mayoritario, corresponde a los apuntados (7), entre los que aparecen una pieza sobre diáfisis en proceso de conformación (¿arpón?); 4 arpones de cuerna ( 1 con tratamiento térmico), 2 enteros de un pequeño tamaño (aprox. $55 \mathrm{~mm}$. de longitud), con sección oval y dientes (3) en el lateral derecho muy poco marcados y sin perforación (uno de ellos porta incisiones de uso; Lám. 9, fig. 1-2), 1 que es un proximal sin orificio, muy parecido a los anteriores pero con posible dentición hacia la izquierda, y con marcas utilitarias (Lám. 9, fig. 5), y 1 mesial de arpón decorado (Lám. 9, fig. 3), de sección triangular, diente marcado y dibujo en el mismo de un escaliforme. Además se cuentan entre los apuntados, un biapuntado sobre diáfisis y un punzón también sobre una esquirla con huellas de uso (liso en lateral). El único útil perforado, es un canino atrofiado de ciervo muy alterado por marcas tafonómicas (Lám. 9, fig. 4). Finaliza esta colección un hueso sin modificar, con marcas decorativas a base de trazos pareados (Lám. 9, fig. 6).

Como en el caso anterior, la matriz preferida en este conjunto es la cuerna de ciervo ( 8 de 13), seguida de las esquirlas (3) y el canino (1), con un número alto de piezas quemadas (6), tanto sobre candiles, como en piezas en conformación o ya acabadas (arpón y biapuntado). La técnica más empleada es la de aserramiento-pulimento (5, con 4 arpones), obteniéndose los apuntamientos preferentemente por incisiones en uno de los laterales de la pieza tanto en la extremidad distal (entre 9 y 6 $\mathrm{mm}$.) como en proximal (entre 19 y $13 \mathrm{~mm}$.). Sobre las diáfisis (biapuntado) el apuntamiento se obtuvo por incisiones longitudinales (extremos entre 19 y $11 \mathrm{~mm}$.). La perforación del canino se realizó mediante incisiones longitudinales y una perforación giratoria (plano de $8 \times 6 \mathrm{~mm}$. y orificio de $3 \times 3 \mathrm{~mm}$.).

Las marcas de uso aparecieron sobre los arpones (incisiones transversales pequeñas) y las del punzón (alisamiento por uso de frotación en uno de sus laterales). 


\subsection{HORIZONTE OC}

\subsubsection{Conjunto lítico (Lám 10)}

Este Horizonte, el más antiguo de los niveles azilienses, contiene algo más de la cuarta parte del total de las piezas inventariadas. Concretamente, un $28 \%$.

a) Raspadores. El grupo de los raspadores vuelve a representar el segundo componente tipológico de la muestra, aunque su número absoluto y relativo es bastante inferior al mostrado por los horizontes anteriores: ni siquiera una cuarta parte (tan sólo un $20 \%$ del total de las piezas catalogadas). En esta ocasión se documenta un predominio notorio de raspadores sobre extremo de lascas y lámina y tipos altos o sobre soportes de tamaño considerable (concentran el $40 \%$ y $45 \%$ de los raspadores, respectivamente). Los raspadores microlíticos o de «botón» son mucho más escasos (un $12 \%$ ).

b) Utillaje microlaminar. Tal como sucedía en la muestra del horizonte anterior, estos tipos constituyen el componente dominante del registro lítico. Hasta tal punto es así que la proporción de este tipo de piezas supera con creces las registradas en cualquiera de los anteriores: más de la mitad las piezas descritas como útiles son microlaminares (en concreto un $55 \%$ ). La estructura compositiva básica resulta prácticamente idéntica a la observada en el Horizonte 0b. Más de la mitad son laminillas de dorso (representan en torno al 54\%). Destaca la presencia de microgravettes (hasta un 20\%). La colección también incluye algunas puntas y laminillas de doble dorso (ambos tipos se sitúan en torno al 10\%), así como algunas escasas puntas azilienses (su presencia apenas supera el $4 \%$ ).

c) Otros grupos. Los buriles superan ligeramente el $7,5 \%$ del total de la colección, alcanzando su representación más baja en la secuencia. Los tipos de substrato tampoco se encuentran muy representados. Denticulados (menos del $0,9 \%$ ), escotaduras ( $3 \%$ aproximadamente), raederas (menos del $0,3 \%$ ) y piezas astilladas (menos del $1,8 \%$ ) ni siquiera suponen un $6 \%$ del total de la colección.

\subsubsection{Conjunto óseo (Lám. 11)}

Para este Horizonte (Oc), aparecieron 7 piezas seleccionadas: una que tiene marcas de carnicería y 6 piezas trabajadas. Solo un vestigio mostraba huellas de tafonomía (colgante de malacofauna; Lám. 11, fig. 3). 

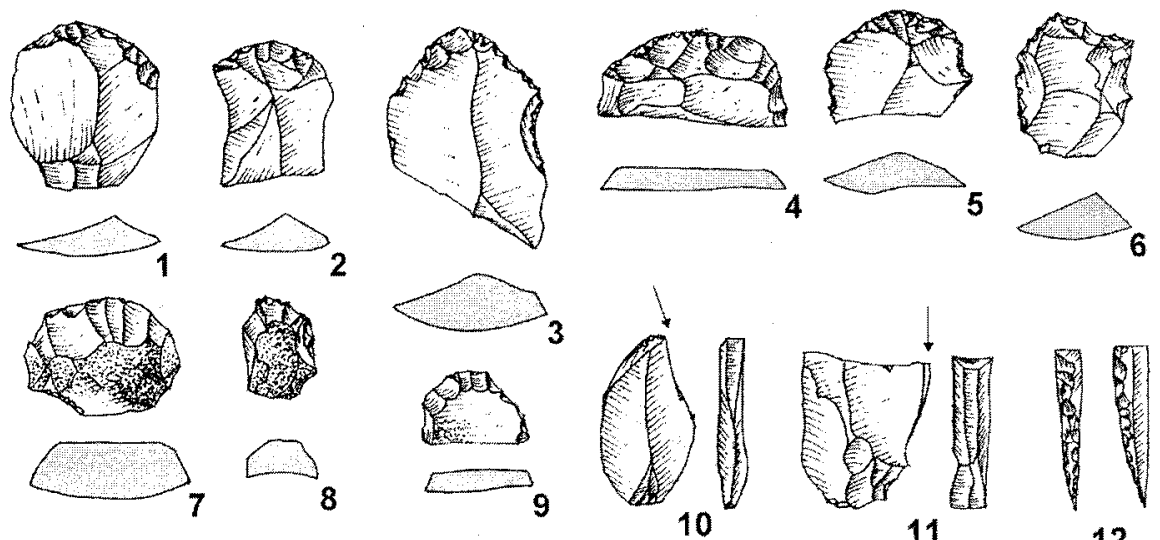

11
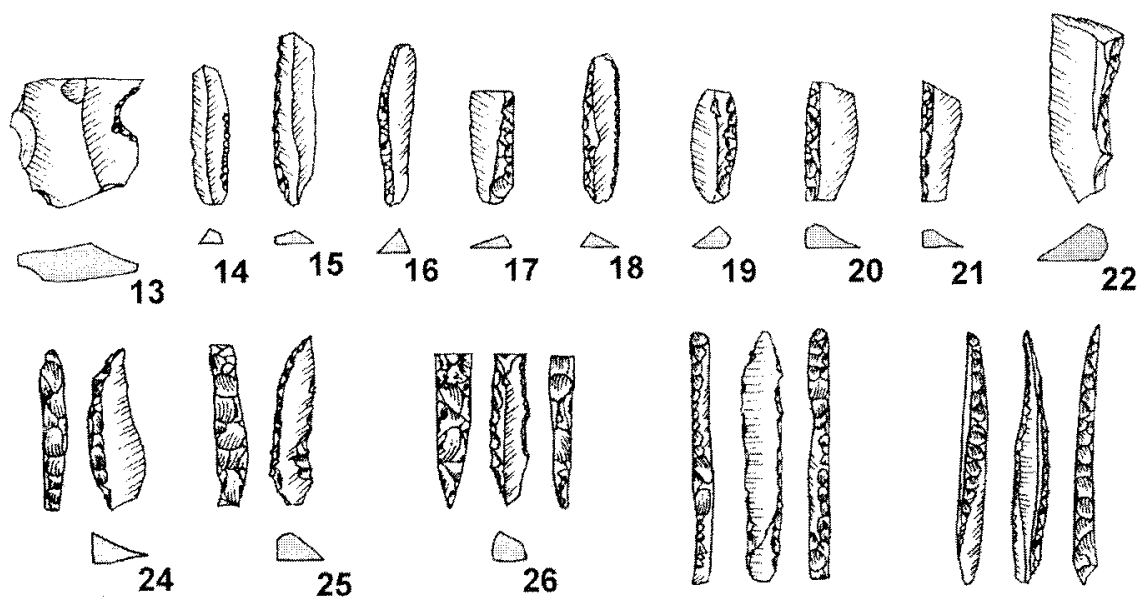

$\bigodot_{19}$
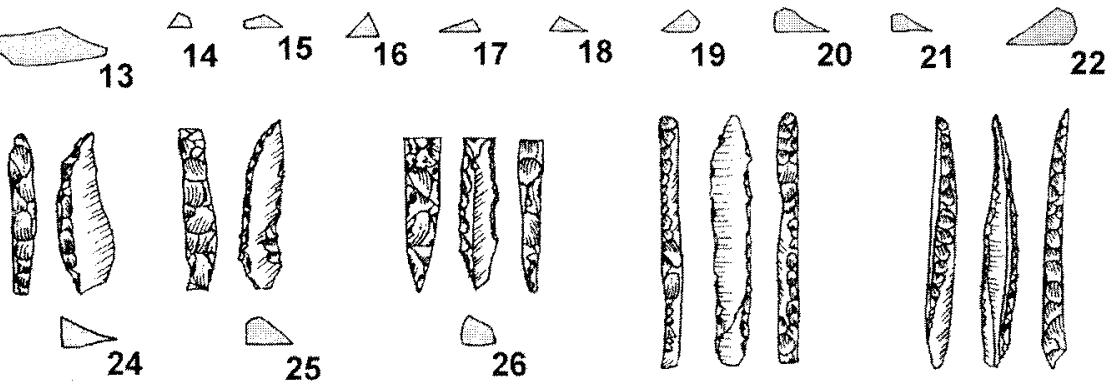

27

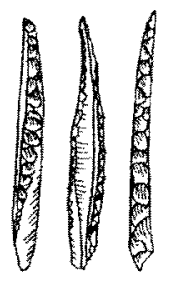

$\square$

28
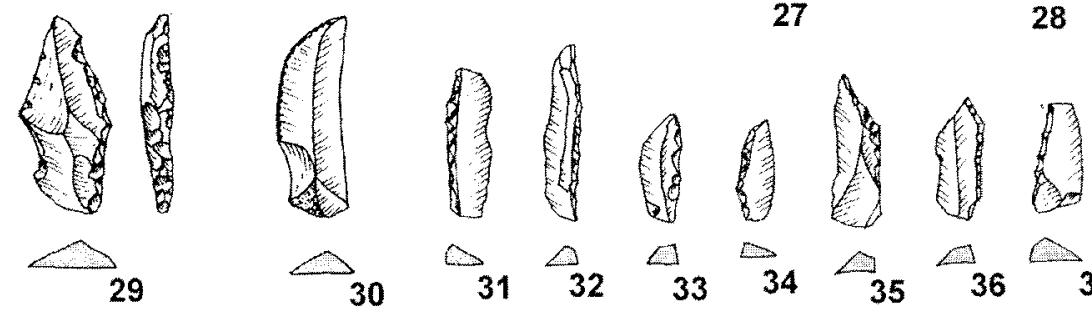

$4_{33}$

34

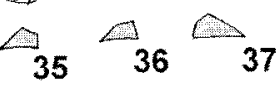

Lám. 10. Muestra de materiales líticos del Horizonte Oc. 1-2, 9: Raspadores simples; 3: Raspador ojival; 4-5, 8: Raspador en hocico plano; 8: Raspador unguiforme; 10 Buril diedro recto; 11: Buril de ángulo sobre rotura; 12: Microgravette; 13: Punta con muesca, 14-21, 31-34, 37: Laminillas de dorso; 22: Lámina con borde abatido total; 35-36: Laminillas de dorso truncadas; 24-25: Puntas azilienses; 26-28: Puntas de doble dorso; 29: Punta atípica; 30: "Laminilla de cabeza curva». 


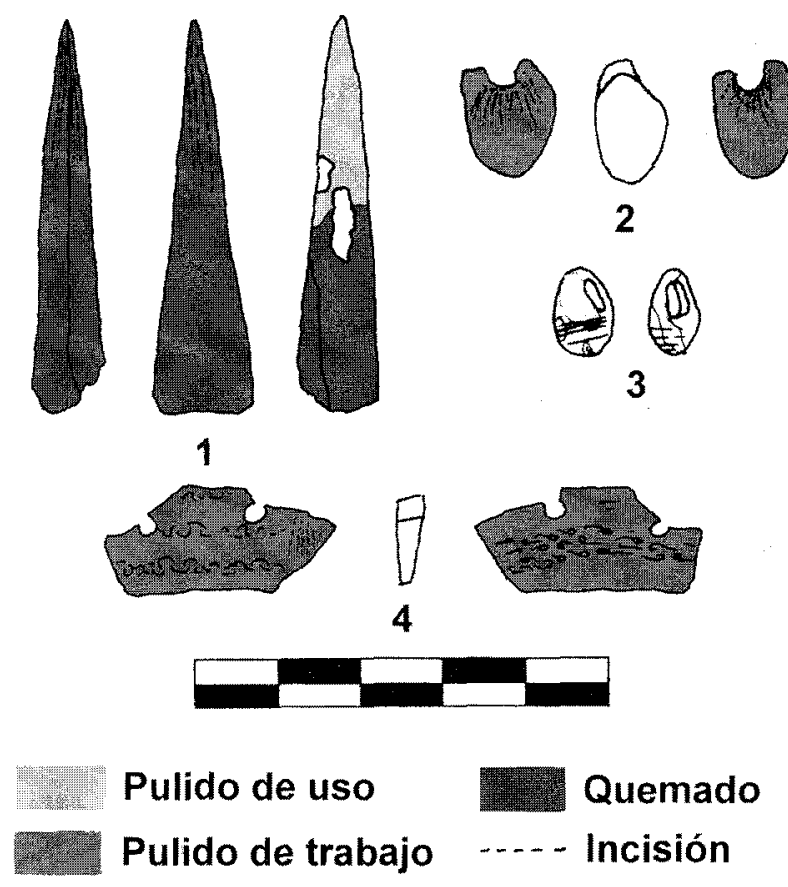

\section{Tafonomia}

Lám. 11. Muestra de materiales óseos (dibujo técnico) del Horizonte 0c. 1. Punzón sobre escápula; 2: Colgante sobre canino atrófico de ciervo; 3: Colgante sobre Trivia europea; 4 :

Esquirla de hueso con doble pertoración.

El único resto de carnicería es un fragmento de cráneo con marcas de despellajamiento y quemado. Las piezas trabajadas corresponden a 3 apuntados y 3 perforados. En el primer grupo, destaca una pieza sobre cuerna quemada y en conformación (posible arpón con máximo de longitud de $53 \mathrm{~mm}$.); después tenemos un punzón quemado sobre un fragmento de escápula (Lám. 11, fig. 1) y el mesial de un posible biapuntado sobre cuerna. Entre los perforados aparecen un fragmento de colgante sobre canino de ciervo posiblemente quemado (Lám. 11, fig. 2), otro colgante sobre Trivia europea (Lám. 11, fig. 3); y por último, una placa muy aplanada sobre una esquirla de ciervo (longitud de $13 \mathrm{~mm}$.), con dos pequeños orificios rotos (Lám. 11, fig 4).

Para realizar los útiles, se seleccionó preferentemente la cuerna $(3,2$ de ellas quemadas), luego una diáfisis quemada (1), el canino de ciervo 
posiblemente también quemado (1) y la Trivia (1). Como técnica de conformación, aparece el aserramiento pulimento (3 de 6), estando el resto de la colección casi sin trabajar. La técnica de apuntamiento empleada fue la de incisiones longitudinales (de unos 10 a $14 \mathrm{~mm}$.), mientras para la perforación se utilizó la incisión lineal y giratoria en el canino; y la presión posiblemente por instrumento, en los otros dos casos: sobre la malacofauna $(4 \times 2 \mathrm{~mm}$.) y la placa de cuerna (circa de $2 \times 2 \mathrm{~mm}$.).

En cuanto a las marcas de uso, mencionar el punzón con señales lisas de frotación en la cara interna del mismo (plano de $25 \mathrm{~mm}$.).

\section{CUEVA OSCURA DE ANIA: CONTEXTUALIZACIÓN INDUSTRIAL}

Los estudios preliminares que presentamos en esta publicación nos han permitido profundizar en algunas de las orientaciones básicas que guían las investigaciones recientes sobre el Aziliense, especialmente en la definición del Aziliense antiguo. Los resultados preliminares del estudio del conjunto lítico aziliense de Cueva Oscura de Ania apuntan que entre los cuatro horizontes existe cierta homogeneidad en la variedad tipológica: abundancia de raspadores sobre extremos de pequeñas lascas y láminas con fracturas proximales; preponderancia de útiles microlíticos, singularmente de hojitas de dorso; escasez relativa de buriles simples sobre fracturas; y presencia consistente de útiles de substrato y buriles. No obstante, estas primeras aproximaciones también parecen señalar diferencias relevantes, perfilándose dos esquemas distintos en atención a las proporciones y estructura compositiva del utillaje. Los Horizontes Oc y Ob muestran una mayor frecuencia relativa del grupo tipológico microlaminar que los Horizontes 0 a y 0 , siendo esta relación inversa en el caso de los raspadores.

\subsection{Los raspadores}

El grupo tipológico de los raspadores en las diversas muestras azilienses de Cueva Oscura de Ania resulta muy similar: piezas muy convencionales, con unas características técnicas y tipométricas muy estandarizadas. Desde un punto de vista tipológico, se aprecia una homogeneidad notable, pudiendo agruparse en tres conjuntos. En primer lugar pueden citarse los tipos "altos" o elaborados sobre soportes espesos (lascas 0 núcleos), correspondientes a taxones carenados y en hombro $u$ hocico. En segundo lugar destacan los raspadores de pequeño tamaño - netamente microlíticos-, fundamentalmente raspadores circulares y unguifor- 
mes, con una tendencia marcada a que el frente ocupe casi todo el contorno de la pieza. Un caso llamativo y bastante abundante es el tercer grupo, formado por tipos de raspadores de tendencia más o menos circular, fabricados sobre extremo de lasca o lámina, cuyos soportes han sido acortados por medio de fracturas proximales. Generalmente clasificados como «raspadores atípicos" por los excavadores de la cueva, un estudio más detenido de las piezas podría aclarar si la "reducción» descrita atendía a necesidades de enmangue de la pieza o, por el contrario, refleja un deterioro de uso.

El predominio de los raspadores en los Horizontes superiores, 0 y $0 \mathrm{a}$, de Cueva Oscura de Ania recuerda el espectro registrado en la cercana cueva de La Paloma. El Nivel 2 de este yacimiento, aziliense, es el que ofrece una mayor proporción de raspadores de toda la secuencia (su índice alcanza el $50 \%$, aunque a buen seguro está sobrevalorado por las carencias en la recogida de utillaje microlaminar inherente a la metodología de excavación imperante en la época en que Eduardo Hernández Pacheco desarrolló sus trabajos de campo). Dentro de este grupo, los tipos sobre lasca constituyen casi la mitad, seguido por los tipos de tendencia circular y, ya en menor medida, nucleiformes y aquillados. Aunque no se cita la existencia de taxones sobre hoja, es posible que esta ausencia se deba a la pauta de clasificación seguida. Si bien ha sido tónica general distinguir láminas de lascas siguiendo criterios métricos, nosotros hemos optado por valorar aspectos tecnológicos y estructurales (Bernaldo de Quirós et alii 1981: 12). Esta disparidad de método cobra relevancia si atendemos al hecho ya comentado de que una mayoría abrumadora de raspadores sobre lámina de Cueva Oscura de Ania han sido acortados y sus soportes podrían describirse como lascas desde el punto de vista de sus proporciones.

La relativamente elevada representación de especímenes circulares, unguiformes y de otros tipos fabricados sobre lascas pequeñas supone una constante en los horizontes analizados. Este hecho confirma que Cueva Oscura de Ania participa netamente de la tendencia progresiva hacia la preferencia de soportes microlíticos que caracteriza la evolución técnica de los raspadores desde los últimos tiempos magdalenienses. En el área del oriente asturiano, estos cambios pueden detectarse en algunos conjuntos occidentales del Magdaleniense superior, como en los niveles 21/23 a 27 de la Cueva de La Riera (González Sáinz 1989: 209), en Posada de Llanes. Centrándonos en la cuenca del Nalón, esta tendencia de aumento de raspadores microlíticos también está documentada en la secuencia de La Paloma. Esta misma pauta puede estar reflejada en el registro arqueológico de Cueva Oscura de Ania. Los resultados preliminares de nuestro estudio sugieren que el proceso de microlitización está acom- 
pañado por otro de estandarización. Esta normalización de tipos de raspadores microlíticos, que contrasta con las técnicas de fabricación de buriles, parece estar acompañada de cierta selección de la materia prima.

\subsection{Los buriles}

La relativamente escasa representación de buriles constatada en Cueva Oscura de Ania tampoco desentona con las pautas generales observadas para el Aziliense. En este sentido deberíamos matizar que nuestro recuento ofrece una presencia de estos tipos bastante más baja que la estimada inicialmente por los excavadores del yacimiento: «los raspadores mantienen un índice levemente superior al de los buriles» (Pérez Pérez 1977: 184). Esto se debe al hecho de que nuestra revisión ha detectado que un elevado número de piezas clasificadas como buriles eran más bien soportes fracturados - habitualmente lascas de cuarcita - sin rastros evidentes de contrabulbos de percusión. Todo parece indicar que este tipo de piezas corresponden a gran parte de aquellas caracterizadas como buriles «de factura descuidada» (Gómez Tabanera et alii 1975: 63; Pérez Pérez 1977: 184).

Ciertamente, la factura de los buriles azilienses de cueva Oscura de Ania resulta bastante elemental. El dominio de taxones sencillos, como buriles de ángulo sobre fractura y toscos buriles diedros (tanto rectos como desviados), es abrumador. Esta escasa preparación morfotécnica vendría a confirmar un aumento genérico de buriles sobre plano natural o fractura frente a los buriles B2 y B3 más elaborados, de acuerdo con una acentuación de ese pragmatismo técnico que caracterizaría el Aziliense (Fernández-Tresguerres Velasco 1995: 204) y que constituiría el punto final de un proceso progresivo de cambio técnico que arrancaría desde las últimas fases magdalenienses (González Sáinz 1989: 211).

\subsection{El utillaje microlaminar}

El espectro tipológico microlaminar de los horizontes azilienses inferiores (Oc-0b) se aproxima al de los últimos tiempos magdalenienses. El predominio de las hojitas de dorso y la presencia progresivamente relevante de microgravettes observados en Cueva Oscura de Ania constituyen una prolongación de la distribución taxonómica típica del utillaje microlaminar durante el Magdaleniense superior final (González Sáinz 1989: 184). Sin embargo, en el estado actual de nuestras investigaciones no podemos 
precisar con exactitud los componentes innovadores presentes en el repertorio tipológico aziliense de Cueva Oscura de Ania. Una de las directrices propuestas al respecto es la tendencia evolutiva de estas puntas, cuya presencia sistemática en los espectros azilienses contrasta con su escasez en los magdalenienses (ibidem: 219). A nuestro parecer, una segunda tendencia podría encontrarse en la generalización de las puntas de doble dorso. La elevada presencia de utillaje microlaminar en Cueva Oscura de Ania parecería confirmar la pérdida de representantes de estos tipos en la cercana Cueva de La Paloma durante el proceso de excavación. Nuestro estudio preliminar ha registrado un predominio relevante de las laminillas de dorso, taxón en el que podrían establecerse varios subgrupos atendiendo a variaciones de tamaño y características morfológicas, aspecto este que será objeto de mayor atención en publicaciones futuras.

El segundo representante en número del grupo microlaminar es el correspondiente a las microgravettes. Se trata de laminillas apuntadas muy estilizadas, de forma lanceolada, con dorso rectilíneo (curvo rara vez) de retoque muy abrupto bipolar, a veces sólo directo. También ofrecen retoque en su filo, a menudo cubriendo toda la longitud de éste; en ocasiones tres cuartas partes de la trayectoria que sigue desde la base a su extremo distal. Este retoque del filo es semiabrupto y profundo cerca del talón y finaliza su recorrido como simple y marginal. En cuanto al extremo proximal de la pieza, no es apuntado y la intersección entre los retoques de dorso y filo le proporciona una forma curvilínea. Combinando variables como tamaño, morfología y variantes y distribución del retoque, este tipo podría subdividirse en, al menos, cuatro grupos. Como hemos comentado al tratar las laminillas de dorso, este aspecto será ampliado en próximos trabajos.

En cuanto a la evolución del grupo microlaminar, se observa una tendencia al aumento de la proporción de laminillas de dorso de base a techo. Este incremento se acompaña del descenso de la representación de microgravettes. El resto de taxones mantiene un comportamiento más estable, aunque llama la atención la ausencia de puntas de doble dorso en el horizonte superior, hecho que corresponde al valor más alto de la secuencia para las laminillas azilienses. Los datos disponibles apuntan a un dominio de las puntas azilienses sobre las microgravettes en los Niveles 2 y 3 superior de la Cueva de Los Azules (Fernández-Tresguerres Velasco 1980). Cueva Oscura de Ania, parece coincidir en el caso de los Horizontes 0 y 0 a pero no en los Horizontes $0 \mathrm{~b}$ y $0 \mathrm{c}$. En los dos primeros las cifras de estos dos tipos están más equilibradas y es muy posible que estas cifras puedan matizarse con la distribución de especímenes entre los diferentes grupos de laminillas de dorso que hemos establecido, pues uno 
de ellos se caracteriza por presentar un perfil rechoncho y tener el dorso ligeramente incurvado. Aplicando el comentado criterio estricto, hemos decidido no incluirlas en el haber de las laminillas de dorso, aunque los estudios originales del registro de Cueva Oscura de Ania así lo hicieran en bastantes casos. Por otra parte, hemos de tener en cuenta que todo apunta hacia el hecho de que el Nivel 2 (Horizontes ob y 0c) de este yacimiento puede encuadrarse dentro del Aziliense antiguo y que el Nivel 1 (Horizontes 0 y 0 a) podría corresponder a una fase arcaica del Aziliense clásico. Aún no disponemos de datos detallados sobre el comportamiento del grupo microlaminar en el resto de estaciones del occidente cantábrico donde empieza a identificarse el Aziliense antiguo (Nivel 2B de la Cueva de la Lluera l; Nivel 5 de la Cueva de los Azules). Todo ello hace pensar que en los primeros momentos del Aziliense la presencia de puntas azilienses aún no es tan consistente como en momentos más avanzados, en beneficio de la representación de microgravettes. No obstante, en el estado actual de la investigación es aventurado realizar afirmaciones categóricas en uno $u$ otro sentido.

El tercer componente relevante en número dentro del grupo microlaminar de Cueva Oscura de Ania es la "punta de doble dorso", un tipo bien definido en una de las primeras publicaciones sobre el yacimiento (Pérez Pérez 1977: 187): se trata de puntas estrechas y simétricas con doble dorso, generalmente obtenidos ambos por retoque bipolar. La sección tiende a ser subrectangular o trapezoidal cuando la laminilla de soporie es fina, variando de trapezoidal a triangular cuando es algo más espesa. El retoque puede respetar el extremo proximal en los casos en que éste no se encuentra fracturado, aunque no son excepcionales especímenes biapuntados. Para su proceso de fabricación parece buscarse la obtención de laminillas relativamente espesas y no es infrecuente que se aproveche el filo en bisel para completar el dorso sin acudir al retoque. Las laminillas de doble dorso observadas en el registro de Cueva Oscura de Ania podrían responder al fruto de la fractura de este tipo de puntas. Para Fernández-Tresguerres (1995: 210; Fernández-Tresguerres Velasco \& Rodríguez Fernández 1990: 133), las puntas de doble dorso suponen una variante morfológica bien diferenciada de las puntas azilienses por su dorso rectilíneo, que las aproxima más a las microgravettes y a las puntas de Sauveterre.

La presencia de puntas azilierises no es particularmente elevada en el registro de Cueva Oscura de Ania. Debemos recordar que la presencia de puntas o laminillas azilienses, sin ser estrictamente un componente innovador, es un elemento característico del Aziliense. Se constata una tendencia al incremento desde momentos terminales del Magdaleniense su- 
perior y se hace especialmente sensible en las secuencias azilienses más tempranas (González Sáinz 1989: 219-220). Centrándonos en el registro de Cueva Oscura de Ania, la proporción de este tipo de puntas no se ajusta exactamente a las cifras obtenidas en otros depósitos azilienses. Sin embargo, tampoco desentona con el panorama esbozado. Quizás estas diferencias puedan explicarse por el hecho de que hemos aplicado un criterio rígido a la hora de clasificar el utillaje lítico, prestando especial atención al microlaminar. Esto ha dado como resultado que algunas piezas consideradas puntas azilienses por los excavadores del yacimiento pasaran a engrosar el número de laminillas de dorso o microgravettes, según el caso.

Desde un punto de vista tecnológico, el grosor de las laminillas empleadas para la fabricación de puntas azilienses parece imposibilitar la obtención de un dorso rectilíneo (González Sáinz 1989: 219). Al menos no como el característico de las microgravettes, cuyos soportes son más delgados. De hecho, son frecuentes las puntas azilienses con dorso rectilíneo en su extremo distal (apuntado y fino) y curvo en su tramo medio y proximal (más grueso). En ultima instancia, es posible que la fabricación de puntas azilienses y microgravettes esté relacionada con dos aspectos: una selección menos especializada del sílex (perceptible sobre todo en productos toscos de talla, descenso del índice laminar, mayor proporción de piezas carenadas y talones lisos) y una mayor necesidad o demanda del utillaje microlaminar (lo que se traduciría en el retoque masivo de laminillas y la obtención de un repertorio microlaminar más diversificado y menos seleccionado). La utilización exclusiva de un tipo concreto de sílex para la fabricación de microgravettes en Cueva Oscura de Ania parecen apuntar hacia esta selección de materia prima, aspecto este en el que profundizaremos en publicaciones futuras.

\subsection{Materiales óseos}

En lo relativo al conjunto óseo, nos encontramos ante unos vestigios muy seleccionados que tienen como característica principal una gran semejanza morfo-tipológica en toda la secuencia Aziliense (NOa, como N1; y NOb-NOc como N2). Sin embargo no creemos que tengamos ente nosotros todos los productos antrópicos óseos de la excavación. Por ejemplo, suponemos que no todas las marcas de carnicería exhumadas en cueva Oscura, son las que aparecen en este recuento (33 de 85), aunque no descartamos que los restos analizados ejemplifiquen las tendencias de la actividad antrópica en las fases finales del Tardiglaciar. Por ello, es normal que se mantenga una presencia mayoritaria de marcas de descarnación y 
un alto porcentaje de huesos con tratamiento térmico, pues este proceder es el que acontece en otras colecciones óseas de este periodo (Adán Álvarez 1997: 321).

Atendiendo a las piezas trabajadas, también es normal que la elección de la materia prima recaiga sobre la cuerna de ciervo, aunque la forma de trabajarla en Cueva Oscura de Ania sea muy clásica (As/Pul). Ya hemos analizado, como durante el Aziliense, aparecen un amplio abanico de posibilidades tanto en los soportes como en las técnicas (Adán Álvarez 1997:328). Sin embargo la colección de Cueva Oscura, aunque coherente consigo misma (desde el 0c, pasando por el ob y 0a, hasta el 0), no muestra esta variedad.

Entre los morfotipos, la presencia mayoritaria corresponde a las piezas apuntadas (17 de 53). Los arpones estudiados (4 del NOb o N2 de las publicaciones de sus excavadores), se encuadran perfectamente en el periodo designado como Aziliense antiguo con tendencias hacia el clásico: así aparecen piezas no muy grandes (menor a $60 \mathrm{~mm}$.), con un primer diente que continua la extremidad distal, y un número de dientes impar, como en las piezas del Aziliense clásico, aunque sin perforación como en los útiles del Aziliense antiguo (Adán Álvarez 1997: 333). La presencia de la decoración sobre un diente de arpón, similar al de La Lluera I y Los Azules, avala esta clasificación en el Aziliense antiguo. El resto de la colección presenta una disminución de tipos, como es propio del Aziliense. Hemos identificado 4 biapuntados (¿anzuelos?), 3 en 0a y 1 en 0c; 3 punzones ( 2 en 0a y 1 0c); y 2 piezas en conformación ( 1 en ob y 1 en $0 \mathrm{c}$ ) y un mesial.

A continuación siguen los útiles perforados (6 de 33), con colgantes muy comunes sobre Trivia ( 2 de 0 a y 1 de $0 c$ ); sobre caninos de ciervo ( 1 de 0 b y 1 de $0 c$ ); y una pieza más especial: una placa de corta longitud, realizada sobre una esquirla de cuerna muy pulimentada, con dos orificios.

Se finaliza este recuento con un útil biselado, cincel (0a), muy similar a los que aparecen en esta fase en otras cuevas asturianas, como la de Azules (Adán Álvarez 1997: 121) y la Riera (ibidem: 266), y una diáfisis decorada ${ }^{2}$ a base de trazos pareados que no desentona entre los motivos de esta fase Aziliense (ibidem: 353).

2 El término decoración implica una realización intencionada que sobrepasa las necesidades más elementales de subsistencia. 


\section{CUEVA OSCURA DE ANIA: PLANTEAMIENTOS CRONOESTRATIGRÁFICOS}

Tanto las escasas informaciones sedimentológicas que disponemos para los niveles azilienses de Cueva Oscura de Ania como la problemática general sobre la estratigrafía de las industrias azilienses dificultan una contextualización cronológica convincente del depósito. En principio, el estudio polínico del yacimiento, realizado por Arlette Leroi-Gourhan (inédito pero presentado en el Coloquio de Talence en 1976), ubicaba estos niveles en torno a la transición Dryas II/Alleröd (inicios del Cantábrico VIII), con una fecha aproximada de $11.700 \mathrm{~B}$. P. si acudimos a las últimas secuencias sedimentológicas establecidas para la Cornisa Cantábrica (Hoyos Gómez 1995: 69). Una de las dataciones radiocarbónicas publicadas para el Nivel 2, concretamente su Horizonte 0b (Pérez Pérez 1992: 642, nota 16 ), de $11.880 \pm 200$ B. P., no desentonaría con esta atribución (recordemos que el Nivel II.2 de la Cueva de Zatoya [Navarra], ubicado en el Cantábrico VIII, ha proporcionado una fecha de $11.620 \pm 360$ B. P.; Hoyos Gómez 1989; 1995: 66). Sin embargo, el resultado del otro análisis disponible, $9.440 \pm 90$ B. P., situaría este nivel en pleno Preboreal. A la hora de valorar las dataciones de Cueva Oscura de Ania debemos tener presente que las muestras, en ambos casos diversos fragmentos de carbón vegetal, fueron analizadas en dos laboratorios diferentes (GIF-5102 es la referencia de la primera, CSIC-362 la de la segunda). Por otra parte, nada sabemos por ahora sobre el proceso de recogida y manipulación de los carbones, si estos estaban agrupados o dispersos o si pudieran existir diferencias de cota entre los mismos. Por todo ello, creemos necesario mantener una actitud de prudencia respecto a la cronología absoluta de estos niveles, al menos hasta contar con más información y disponer de nuevos análisis.

La cronologia propuesta por Arlette Leroi-Gourhan fue desestimada en estudios posteriores. Juan Fernández-Tresguerres (1980: 125) propuso en un primer momento, sobre la base de su situación cultural, una edad más joven para estos niveles y apuntó la posibilidad de que ambos pudieran corresponder al Preboreal (menos de 9.800 B. P.). Por su parte, César González Sainz (1989: 157) interpretó que el depósito aziliense de Cueva Oscura de Ania representaba la transición Dryas III/Preboreal (finales del Cantábrico IX; en torno a 9.800 B. P.). El argumento esgrimido para ello es que creyó identificar en las descripciones del yacimiento los numerosos problemas estratigráficos que plantea la diferenciación de estos dos episodios sucesivos en la mayoría de los registros asturianos y cántabros. Más concretamente, que la capa de arcillas blancas que parece individualizar los lechos Magdalenienses y Azilienses (Gómez Tabanera et alii 
1975: 65; Pérez Pérez 1977: 191) pudo formarse durante la fase conocida como Cantábrico VIII/Alleröd (González Sáinz 1989: 155).

En ausencia de datos sedimentológicos de primera mano, el depósito arqueológico de los niveles superiores de Cueva Oscura de Ania, en especial sus conjuntos líticos y óseos, podría resultar clave en esta polémica entre cronologías altas y bajas, sobre todo si atendemos a los rasgos arcaicos de su utillaje. César González Sáinz (1989: 160) vinculó las fases templadas del Alleröd con pervivencias magdalenienses consistentes (en especial con la presencia de arpones magdalenienses de doble hilera de dientes) y minimizó la influencia de posibles innovaciones azilienses. Argumentaba así la ausencia en la Cornisa Cantábrica de una etapa de transición tan clara como en los Pirineos. Sin embargo, las propuestas formuladas más recientemente por Juan Fernández-Tresguerres (1995) y Gema Adán (1997: 309) se inclinan por confirmar la presencia de manifestaciones azilienses inequívocas durante el Alleröd. Sus argumentos toman como punto de partida las dataciones obtenidas para los primeros contextos azilienses de la Cueva de Los Azules (Nivel 5), identificados en un primer momento como correspondientes a un Magdaleniense superior (Fernández-Tresguerres Velasco 1980: 33) pero atribuido al Aziliense antiguo una vez se solucionaron los problemas estratigráficos que presentaba y pudo diferenciarse netamente del Nivel 6, efectivamente Magdaleniense: «(...) el fondo del vestíbulo contenía restos de industria aziliense, en la entrada los materiales eran magdalenienses. El nivel 5 se encuentra en una cubeta posiblemente originada por un curso de agua que lavó parte de los niveles magdalenienses» (Fernández-Tresguerres Velasco \& Rodríguez Fernández 1990: 131; cfr. Fernández-Tresguerres Velasco 1995: 210; 1997: 191-192; Fernández-Tresguerres Velasco \& Junceda Quintana 1992: 91; Hoyos Gómez 1995: 65).

El repertorio lítico de los Horizontes Ob y oc de Cueva Oscura de Ania se asemeja a lo conocido de los contextos azilienses de la Cueva de La Lluera I (Nivel 2A), donde se ha constatado la presencia de raspadores circulares de pequeño tamaño, y hojitas o puntas alargadas y de doble dorso (Rodriguez Asensio 1990: 16). En esta misma dirección apunta la similitud entre la decoración del Arpón exhumado en este mismo nivel de Lluera (ibidem: 17) y la del fragmento de Arpón decorado localizado en el Horizonte Ob de Cueva Oscura de Ania. Sin embargo, ante las pocas informaciones disponibles actualmente para Lluera I, el referente inevitable para una contextualización más precisa del singular conjunto lítico de Cueva Oscura resulta ser la capa aziliense inferior de Los Azules (Nivel 5), ubicado en el Alleröd/Cantábrico VIII (Hoyos Gómez 1995: 64-65). En el mismo, además de un Arpón plano con decoración similar a la del fragmento de 
Cueva Oscura de Ania y a la del Arpón de Lluera I, también se constata la presencia de puntas de doble dorso y raspadores cortos de tendencia más o menos circular (Fernández-Tresguerres Velasco 1995: 210; FernándezTresguerres Velasco \& Rodríguez Fernández 1990: 131). La punta de doble dorso se perfila como elemento clave en la diferenciación del Aziliense antiguo, horizonte industrial aún mal definido y poco conocido que se propone como estadio intermedio entre el magdaleniense y el Aziliense clásico (Fernández-Tresguerres Velasco 1995: 210-211; 1997: 195). Todas estos consideraciones vendrían a confirmar las suposiciones de una cronología Alleröd/Cantábrico VIII manifestadas por una de nosotros (Adán Álvarez 1995: 309; 1997: 85) para el Nivel 2 de Cueva Oscura de Ania.

Hasta la fecha, la atribución de depósitos del Aziliense antiguo en la cuenca Nalón parecía confirmada para el Nivel 2A de La Lluera y apenas sugerida, no sin reservas, para el Nivel 2 de Cueva Oscura (FernándezTresguerres Velasco 1995: 201). Este panorama se completaría, para el caso de Asturias, con el Nivel 5 de la Cueva de los Azules y los Niveles 25 y 26 de la Cueva de La Riera (ibidem: 210-211). A nuestro parecer, la presencia de puntas de doble dorso en el Nivel 24 de La Riera (Straus \& Clark 1986: 160) no desentona con el panorama que se está esbozando. La industria contenida en esta unidad estratigráfica podría contar con elementos azilianizantes. En ella puede apreciarse una tendencia al aumento espectacular del repertorio microlítico, la incorporación de algunas puntas azilienses y el número creciente de microgravettes (González Sáinz 1989: 60 y 64). Aspecto éste que cobra una nueva dimensión si tenemos en cuenta los dos tramos paleoclimáticos apreciables en su diagrama polínico (Leroi-Gourham 1986: 60). Estas consideraciones aconsejarían una revisión de los materiales arqueológicos de Riera 24 para concretar si su filiación industrial se aproxima a la de los contextos que empiezan a conocerse del Aziliense antiguo o, por el contrario, corresponde al Magdaleniense superior final.

Por lo que respecta a los Horizontes 0 y 0 a de Cueva Oscura de Ania, posiblemente equivalentes al Nivel 1 publicado por sus excavadores (Gómez Tabanera et alii 1975; Pérez Pérez 1977), los resultados preliminares de nuestra revisión apuntan que pudieran representar un Aziliense clásico, quizás con rasgos ligeramente arcaizantes. Para matizar este aspecto se hace imprescindible disponer de datos detallados sobre el comportamiento del grupo microlaminar en el resto de estaciones del occidente cantábrico donde empieza a identificarse el Aziliense antiguo (Nivel 2B de la Cueva de la Lluera I; Nivel 5 de la Cueva de los Azules). En la industria lítica de ambos horizontes los tipos de substrato tienen una representación relativamente nutrida; abundan los raspadores 
sobre lasca de pequeño tamaño y tendencia circular; los buriles denotan una factura más simple que los horizontes precedentes; la presencia de puntas azilienses y microgravettes es moderada; las laminillas de dorso son abundantes y la punta de doble dorso deja de ser un elemento importante en el repertorio microlaminar. Todos estos aspectos permiten suponer que estos horizontes arqueológicos de Cueva Oscura de Ania podrían constituir referentes excelentes para determinar con mayor precisión la situación cronoestratigráfica del nivel aziliense de La Paloma (Nivel 2).

Aún es pronto para afirmarlo con rotundidad, pero la industria lítica del Nivel 1 (Horizontes 0 y 0 a) parece aproximarse a la registrada en los lechos inferiores del Nivel 3 de la Cueva de Los Azules (3f-3e) y al nivel aziliense mas avanzado de la Cueva de La Riera (Nivel 27), teniendo siempre presentes las matizaciones ya consabidas respecto a la precisión cronológica del amplio paquete sedimentario superior de este último yacimiento (los Niveles 24 a 28). En este sentido, cabe señalar cómo las dataciones radiocarbónicas definidas en el depósito estratigráfico de Los Azules para este momento se sitúan en 11.000 y el 9.500 , a caballo entre Dryas III/Cantábrico IX y Preboreal/Cantábrico X. Precisamente, ambas alternativas cronológicas fueron planteadas por una de nosotros (Adán Álvarez 1995: 434; 1997: 85) para el Nivel 1 de Cueva Oscura de Ania. Aunque se hace necesario un estudio más completo de los materiales del yacimiento, poco más podrían avanzar al respecto sin un apoyo sedimentológico.

\section{RECAPITULACIÓN}

\subsection{Cueva Oscura de Ania y la definición del Aziliense antiguo}

Los datos obtenidos en nuestra revisión del registro arqueológico de Cueva Oscura de Ania parecen confirmar que los niveles azilienses del yacimiento corresponden tanto a las etapas más tempranas como a un avance hacia las clásicas de este período, tal como se vienen definiendo en estos últimos años (Fernández-Tresguerres Velasco 1995). En este contexto, la presencia de puntas de doble dorso se erige como un elemento clave para una definitiva ubicación cronoestratigráfica del depósito. La singular abundancia de este taxón lítico en sus Horizontes ob y oc parece distanciarles de los espectros azilienses clásicos y asegurar su correspondencia con momentos más tempranos que acaso podríamos calificar como de transición. Los repertorios instrumentales ca- 
racterísticos de este horizonte, aún poco conocidos, podrían caracterizar la mitad occidental de la Cornisa Cantábrica durante el Alleröd/Cantábrico VIII. Cuando menos, en este sentido parece señalar la presencia de piezas de doble dorso en el espectro tipológico microlaminar registrado en los niveles azilienses inferiores de la Cueva de Los Azules (Nivel 5), la Cueva de La Lluera I (Nivel 2A), la Cueva de La Riera (niveles 24 a 27) y Cueva Oscura de Ania (Horizontes ob y 0c). Dentro de este panorama, el contexto industrial de Los Azules era el mejor definido hasta la fecha: hojitas de doble dorso (bien total, bien parcial), y algunas puntas de doble dorso, aunque frecuentemente uno de ellos es menor que el opuesto (Fernández-Tresguerres Velasco \& Rodríguez Fernández 1990: 132). A él viene unirse el Aziliense antiguo de Cueva Oscura de Ania, en claro proceso de transformación, a juzgar por el conjunto óseo.

Aunque aún hemos de profundizar en nuestra revisión de los materiales de Cueva Oscura de Ania y contrastar nuestras conclusiones sobre el terreno, parece claro que este yacimiento puede erigirse en una estación clave para ampliar el conocimiento sobre el Aziliense antiguo, su origen y evolución. Máxime si tenemos en cuenta tanto lo fragmentario y restringido que aparecía hasta la fecha el registro aziliense en la cuenca del Nalón. Por otro lado, esta posible importancia del yacimiento incrementaría de confirmarse que sus Horizontes $0 \mathrm{~b}$ y $0 \mathrm{c}$ se situaran cronoestratigráficamente en el Alleröd/Cantábrico VIII. Esta fase plaeoclimática, mal representada en el conjunto de la Cornisa Cantábrica, dentro de Asturias sólo ha podido identificarse sin dudas razonables en los procesos de erosión superficial del Nivel I de la Sala II de la Cueva de Las Caldas (San Juan de Priorio), el Nivel $B_{2}$ de Cova Rosa (Sardedo, Ribadesella) y el Nivel 5 de la Cueva de los Azules (Hoyos Gómez 1995: 63-65). Curiosamente, Cova Rosa $B_{2}$ ha sido definido desde un punto de vista industrial como de transición entre el Magdaleniense superior final y el Aziliense (Jordá Cerdá et alii 1982) y bien pudiera representar — cuando menos en su tramo superior - un Aziliense antiguo. Sin embargo, los problemas que plantea ese yacimiento aconsejan prudencia.

En cualquier caso, parece claro que la cuenca del Nalón se incorpora con fuerza al conocimiento más profundo del origen y el desarrollo del Aziliense en el occidente de la Cornisa Cantábrica, no sólo (aunque sí principalmente) gracias a los depósitos de las cuevas de La Lluera I y Oscura de Ania. Las consideraciones iniciales sobre el yacimiento de Sofoxó I (Vega del Sella 1921: 69) cobran una nueva dimensión a la luz de los avances efectuados en la caracterización del Aziliense antiguo y la constatación de las dificultades que puede suscitar en registros de re- 
solución baja su distinción respecto a los depósitos terminales del Magdaleniense (Fernández-Tresguerres Velasco 1995: 210-211; 1997). En primer lugar, no parecen existir argumentos de peso para dudar del criterio del Conde de la Vega del Sella. A pesar de las reservas que despierta el estado de la investigación cuando éste desarrolló sus trabajos, es una figura que ha dado muestras inequívocas de reunir una intuición extraordinaria y un rigor científico poco común en aquellos momentos. Por supuesto, estas consideraciones no pretenden invalidar las conclusiones obtenidas por trabajos más recientes, especialmente la exhaustiva revisión del yacimiento realizada por Soledad Corchón y Manuel Hoyos (1972/73), sino llamar la atención sobre el hecho de que en determinadas circunstancias - y la Cueva de Sofoxó I parece reunirlas- la identificación el Aziliense antiguo resulta prácticamente imposible o, cuando menos, muy problemática. Que este horizonte estuviera representado en Sofoxó I no pasa de ser una mera hipótesis difícil de contrastar en la actualidad (sobre todo si tenemos en cuenta que se excavó en unos años que la recogida de utillaje microlaminar no era moneda común) pero que cobra algo de fuerza si tenemos en cuenta los resultados del análisis morfotécnico de su colección ósea (Adán Álvarez 1995: 484-490; 1997: 106-107).

\subsection{Cueva Oscura de Ania y la evolución del Aziliense en la cuenca del Nalón}

Parece clara la correspondencia del Nivel 1 de Cueva Oscura de Ania (Horizontes 0 y 0 a) con un momento de transición hacia un Aziliense clásico. En cualquier caso, el análisis tecnomorfológico de la colección ósea revisada hasta la fecha señala que no tenemos representado su tránsito hacia las fases más avanzadas de éste (Aziliense final), algo hacia lo que también apuntaría la escasa relevancia del utillaje microlaminar típicamente geométrico y piezas fabricadas con la técnica de microburil en el tramo superior de la secuencia. Como es bien sabido, la incorporación de este tipo de piezas se produce en un horizonte relativamente avanzado del Aziliense, que no parece anterior a la segunda mitad del Dryas III/Cantábrico IX. Sin embargo, estos componentes tecnotipológicos no resultan particularmente reveladores en el registro aziliense asturiano. Esto es así por la poca representación que tiene este tipo de piezas en el occidente cantábrico (Fernández-Treguerres Velasco 1995: 217). En cualquier caso, poco más puede aportar el avance en nuestro reestudio de materiales. Nuevamente una revisión de la estratigrafía sobre el terreno y una 
contrastación sedimentológica se erigen como elementos claves para discernir el alcance real del registro aziliense de Cueva Oscura de Ania.

De los primeros datos disponibles sobre Cueva Oscura de Ania se deduce que el utillaje microlaminar tiene una presencia mayor en los niveles azilienses que en el último magdaleniense (Gómez Tabanera et alii 1975; Pérez Pérez 1977). De confirmarse esta tónica, este registro encajaría bien en las propuestas recientes sobre una tendencia de microlitización del utillaje de dorso desde las fases magdalenieses más tardías, más concretamente desde el Dryas II/Alleröd (González Sáinz 1989: 184). No obstante, desconocemos la posición cronoestratigráfica precisa del nivel Magdaleniense superior de Cueva Oscura de Ania. Lo poco avanzado de nuestra revisión de estos materiales desaconseja adelantar hipótesis al respecto. Todavía no disponemos de datos sobre el incremento relativo de las puntas de doble dorso, las puntas azilienses y las microgravettes con respecto las laminillas que pudiera experimentar el depósito desde su último nivel magdaleniense hasta los primeros horizontes azilienses. En este contexto, aún debemos analizar si existe un aumento proporcional de las puntas, tal como parece suceder en muchos otros registros cantábricos (ibidem: 220). Esta es una tendencia que parece tener un desarrollo a largo plazo, pues se detecta desde fases no muy tardías del Magdaleniense superior final que aún no sabemos a ciencia cierta si están representadas en los depósitos de cueva Oscura de Ania excavados.

\section{CONCLUSIONES FINALES}

Nuestra revisión de materiales procedentes Cueva Oscura de Ania permite afirmar que este yacimiento ha de ocupar necesariamente un papel preponderante en el conocimiento del Aziliense en la cuenca del Nalón, dados los problemas que suscitan las vicisitudes sufridas por los registros de las vecinas Cuevas de La Paloma y Sofoxó I; la destrucción de Cueva Oscura de Perán (Fernández-Tresguerres Velasco 1980: 50) y la parquedad de noticias procedentes de la Cueva de La Lluera I (Rodríguez Asensio 1990) y la Cueva del Ángel (Adán Álvarez 1995: 309-315; 1997: 55-57; Adán Álvarez \& Jordá Pardo 1992). A la espera de contar con publicaciones que detallen en profundidad el registro de éstos últimos yacimientos y que ofrezcan los resultados de las excavaciones realizadas a finales de la década de 1970 en La Paloma, Cueva Oscura de Ania ofrece la secuencia Aziliense arcaico más completa del Nalón, además de una densidad de restos poco usual. El tamaño de la muestra añade valor, si cabe, a su depósito arqueológico. La constatación de tener representado 
el Aziliense antiguo superpuesto a niveles presumiblemente del Magdaleniense superior final sitúa Cueva Oscura de Ania en una situación de privilegio para completar la imagen del origen y evolución del Aziliense esbozada los últimos años, incorporándose, sin ningún genero de dudas, al repertorio de yacimientos donde se documenta este horizonte cronológico.

Madrid/Oviedo, diciembre de 1999-febrero de $2000^{3}$

\section{Addenda:}

Con posterioridad a la redacción definitiva de este articulo hemos recibido el informe sobre los materiales cerámicos atribuidos al Horizonte 0-superficial de Cueva Oscura de Ania, realizado por Iván Muñiz. El lote, compuesto por 10 fragmentos de cerámica, 1 de teja y un pequeño gelifracto de caliza que se presta a confusiones, muestra una gran heterogeneidad y dificultades de atribución cronológica al mostrar características tipológicas genéricas de la alfarería común de uso doméstico que se prolonga hasta nuestros días. De los tres grupos establecidos, aquel integrado por un mayor número de fragmentos (siglados como c-1/4, c-12 del cuadro $3 \mathrm{C}$ y c11 del 2C) presenta una filiación pleno/bajomedieval, con probable perduración en etapa moderna. En trabajos posteriores se profundizará en esta cuestión.

\section{BIBLIOGRAFÍA}

ADÁN ÁlvAREZ, Gema E. (1995): Industria ósea del Tardiglaciar en Asturias: análisis arqueozoológico y estudio de los métodos de trabajo sobre el utillaje óseo; tesis doctoral inédita; Universidad de Salamanca, Salamanca.

Adán Álvarez, Gema E. (1997): De la Caza al útil. La industria Ósea del Tardiglaciar en Asturias; Servicio de Publicaciones del Principado de Asturias, Oviedo.

AdÁn Álvarez, Gema E. (en prensa). El Servicio de Investigaciones Arqueológicas de Asturias (S.I.A.): F. Jordá Cerdá (1952-1964), en 31 Congreso de Arqueología Peninsular. Vila Real, UTAD, entre el 21 y el 27 de Septiembre de 1999.

AdÁn Álvarez, Gema E. \& Jordá PARDo, Jesús (1992): La secuencia estratigráfica de la Cueva del Ángel (Tuñón, Santo Adriano), y el material arqueológico asociado, en Excavaciones Arqueológicas en Asturias, 1987-1990, 1: 255-257; Servicio de Publicaciones del Principado de Asturias, Oviedo.

3 Los autores del texto desean expresar su agradecimiento a Don Enrique García Tessier, director del Museo Arqueológico de Asturias (Oviedo), y al personal laboral de dicha institución por las facilidades que nos han prestado a la hora de revisar los materiales arqueológicos de Cueva Oscura de Ania. 
ALMAGRo BASCH, Martín (1944): "Los problemas del Epipaleolítico y Mesolítico en España»; Ampurias, 5: 1-38.

Almagro BASCH, Martín (1963): España prehistórica, en Ramón MenÉndez Pidal, ed.: Historia de España, Tomo I, Vol. 1: 245-285; Madrid. 3. ${ }^{a}$ edición.

Barandiarán Maestu, Ignacio (1967): El Paleomesolítico del Pirineo Occidental. Bases para una sistematización tipológica del instrumental óseo paleolítico; Monografías Arqueológicas, III; Universidad de Zaragoza, Zaragoza.

BaRANDIARÁN MAestu, Ignacio (1971): "La Cueva de La Paloma (Asturias)"; Munibe, XXIII (2/3): 255-283.

BARANDIARÁN MAESTU, Ignacio (1973): Arte mueble del Paleolítico cantábrico; Monografías Arqueológicas, XIII; Universidad de Zaragoza, Zaragoza.

BARANDIARÁN MAESTU, Ignacio (1988): «Datation C14 de l'art mobilier magdalénien cantabrique»; Prehistoire Ariégoise, XLIII: 63-85.

Bernaldo de Quirós, Federico; Cabrera, Victoria; Cacho, Carmen \& Vega, L. Gerardo (1981): «Proyecto de análisis técnico para las industrias líticas»; Trabajos de Prehistoria, 38: $9-37$.

CANo Díz, José (1977): Vestigios de arte rupestre bicromo en Cueva Oscura de Ania, Las Regueras (Asturias), en Actas del XIV Congreso Nacional de Arqueología: 197-200; Zaragoza.

Corchón Rodriguez, M. a Soledad (1971): Notas en torno al arte mueble asturiano; Opera Minora, 2; Universidad de Salamanca, Salamanca.

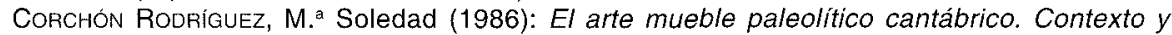
análisis interno; Centro de Investigación y Museo de Altamira/Monografías, 16; Ministerio de Cultura, Madrid.

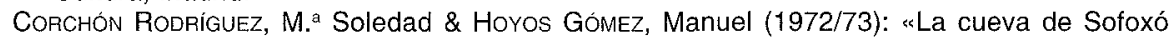
(Las Regueras, Asturias)"; Zephirus, XXIII-XXIV: 39-100.

Eguren, Enrique (1919): Discurso leído en la solemne apertura del curso académico de 19191920; Universidad de Oviedo, Oviedo.

Fernández Rapado, R. \& Mallo VIEScA, M. (1965): «Primera cata de sondeo en Cueva Oscura»; Boletín del Instituto de Estudios Asturianos, XII: 83-90.

FERnÁNDEZ-TRESGUERRES VEL.ASCO; Juan A. (1980): El Azillense en las provincias de Asturias y Santander, Centro de Investigación y Museo de Altamira/Monografías, 2; Ministerio de Cultura, Madrid.

- (1990): El Epipaleolítico en Asturias: El fin de los cazadores recolectores, en Historia de Asturias, Vol. I: 85-100; Prensa Asturiana, Oviedo.

- (1994): El arte aziliense, en Teresa Chapa Brunet \& Mario Menéndez Fernández, eds.: Arte Paleolítico: 81-95; Complutum, 5; Editorial Complutense, Madrid.

- (1995): El Aziliense de la región cantábrica, en Alfonso Moure Romanillo \& César GonZÁLEZ SÁINZ, eds.: El final del Paleolítico cantábrico: 199-224; Universidad de Cantabria, Santander.

- (1997): Arpón decorado Aziliense, en Enrique García Tessier, ed.: Nuestro Museo. Boletín Anual del Museo Arqueológico de Asturias, 1: 191-197; Consejería de Cultura del Principado de Asturias, Oviedo.

Fernández-Tresguerres Velasco; Juan A. \& Junceda Quintana, Fernando (1994): Los arpones azilienses de la Cueva de Los Azules (Cangas de Onís, Asturias), en José A. LASHERAS, ed: Homenaje al Dr. Joaquín González Echegaray. 87-95; Centro de Investigación y Museo de Altamira/Monografías, 17; Ministerio de Cultura, Madrid.

Fernández-Tresguerres Velasco; Juan A. \& Rodríguez Fernández, Juan J. (1990): «La Cueva de los Azules (Cangas de Onís)»; Excavaciones Arqueológicas en Asturias, 1 (1983-1986): 129-133.

FORTEA PÉREZ, Javier (1981): «Investigaciones prehistóricas en la cuenca media del Nalón»; Zephyrus, XXXII-XXXIII: 5-16.

Gomez Tabanera, José M. (1975a). "La Edad de Piedra en la Cuenca del Bajo Nalón (Asturias)». Valdedios: 63-91.

- (1975b): "Catalogue des grottes et gisements préhistoriques dans l'est des Asturies»; Bulletin de la Société Préhistorique de l'Ariège, XXX: 29-57. - (1980): La caza en la Prehistoria (Asturias, Cantabria Euskal-Herría); Ediciones Istmo, Madrid. 
Gómez Tabanera, José M.; Pérez Pérez, Manuel \& Cano Díaz, José (1975): «Première prospection de "Cueva Oscura de Ania" dans le bassin du Nalon (Las Regueras, Oviedo) et conaissance de ses vestiges d'Art Rupestre"; Bulletin de la Société Préhistorique de l'Ariège, $X X X: 59-69$.

GonzÁlez ECHEGARAY, Joaquín (1966): «Sobre la cronología de la glaciación Würmiense en la Costa Cantábrica»; Ampurias, XXVIII: 1-12.

GONZÁlEZ SAINZ, César (1989): El Magdaleniense superior-final de la región cantábrica; Tantin, Santander.

Hernández Pacheco, Eduardo (1919): La caverna de la Peña de Candamo; Comisión de Investigaciones Paleontológicas y Prehistóricas, 24; Madrid.

- (1922): "Plaques d'Ardoise et os gravés de la Caverne de La Paloma en Asturies»; Revue Anthropologique: 334-341.

- (1923a): La vida de nuestros antecesores paleolíticos según os resultados de las excavaciones de La Paloma (Asturias); Comisión de Investigaciones Paleontológicas y Prehistóricas, 31; Madrid.

- (1923b): Grabado esotérico del magdaleniense medio de la Cueva de la Paloma (Asturias), en Actas y Memorias de la Sociedad Española de Antropología, Historia Natural y Prehistoria, II: 10-22; Madrid.

- (1954): Reseña de las colecciones prehistóricas y deducciones de su estudio; Museo Nacional de Ciencias Naturales, Madrid.

- (1959): Prehistoria del Solar Hispano. Orígenes del Arte Pictórico; Serie de Ciencias Naturales, tomo XX; Real Academia de Ciencias Exactas, Físicas y Naturales, Madrid.

Horos Gómez, Manuel (1989): Estudio sedimentológico del yacimiento de la Cueva de Zatoya, en Ignacio Barandiarán y A. Cava, eds.: El yacimiento prehistórico de Zatoya (Navarra): 221-229; ; Trabajos de Arqueotogía Navarra, 3.

- (1995): Paleoclimatología del Tardiglacial en la Cornisa Cantábrica basada en los resultados sedimentológicos de yacimientos arqueológicos de yacimientos kársticos, en Alfonso Moure Romanillo \& César González SÁinz, eds.: El final del Paleolítico cantábrico: 15-75; Universidad de Cantabria, Santander.

Hoyos Gómez, M.; Martinez Navarrete, M. I.; Chapa Brunet, T.; Castaños, P. \& Sanchíz, F. B. (1980): La Cueva de La Paloma. Soto de Las Regueras (Asturias); Excavaciones Arqueológicas en España, 116; Ministerio de Cultura, Madrid.

JORDA CERDÁ, Francisco (1952): «Sobre unos huesos grabados magdalenienses»; Boletín del Instituto de Estudios Asturianos ${ }_{\perp}$ XVII: 370-377.

- (1957): «Guijarro pintado de tipo aziliense en la Cueva del Pindal»; Zephyrus, VIII: 269-274.

- (1963): «El Paleolítico Superior Cantábrico y sus industrias»; Saitabi; XIII; 3-22.

- (1976): Guia de las cuevas prehistóricas asturianas; Colección Popular Asturiana, 11; Ayalga, Gijón.

- (1980): Prólogo, en Manuel Hoyos Gómez, María Isabel Martínez Navarrete, Teresa Chapa Brunet, $P^{\star \star \star}$ Castaños \& $F^{\star \star \star}$ B. SANChiz (1980): La Cueva de La Paloma. Soto de Las Regueras (Asturias): 11-17; Excavaciones Arqueológicas en España, 116; Ministerio de Cultura, Madrid.

Jorda Cerdó, F.; Fuentes Gomez, A.; Hoyos Gómez, M.; Soto, E.; Rey, J. \& Sanchiz, F. B. (1982): Cova Rosa-A; Departamento de Prehistoria y Arqueología de la Universidad de Salamanca, Salamanca.

LAVILle, Henri \& Hoyos Gómez, Manuel (1981): Estudio Geológico de la Cueva de Rascaño, en Joaquín GonzAlez ECHEgaray \& Ignacio Barandiarán MAESTU, eds.: El Paleolítico Superior de la Cueva de Rascaño (Santander): 191-210; Centro de Investigación y Museo de Altamira/Monografías, 3; Ministerio de Cultura, Madrid.

LeROI-Gourhan, Arlette (1986): The palynology of La Riera Cave, en Lawrence G. STRAus \& Geoffrey A. CLARK, eds.: La Riera Cave. Stone Age hunther-gatherer adaptations in Northern Spain: 59-64; Antropological Research Papers, 36; Arizona State University, Tempe.

LLOPIS LLADÓ, N. (1956): «La fauna y los sedimentos de la Cueva de Tuñón (Asturias); Speleon, VII $(1,2,3,4): 145-153$.

Martínez NAVARRete, María Isabel \& Chapa BRUnet, Teresa (1980): La industria prehistórica de la Cueva de La Paloma (Soto de las Regueras, Asturias), en M. Horos Gómez, M. I. martínez Navarrete, T. Chapa Brunet, P. Castaños \& F. B. Sanchiz (1980): La Cueva de La Paloma. Soto de Las Regueras (Asturias): 115-204; Excavaciones Arqueológicas en España, 116; Ministerio de Cultura, Madrid. 
Martinez Santaolalla, Julio (1946) [1941]: Esquema paletnológico de la Península Ibérica; Madrid. 2. ${ }^{a}$ edición.

OBERMAIER, Hugo (1985) [1925]: EL hombre fósil; Istmo, Madrid.

Pérez Pérez, Manuel (1977): Presentación de algunos materiales procedentes de Cueva Oscura de Ania, Las Regueras (Asturias), en Actas del XIV Congreso Nacional de Arqueología: 179-196; Zaragoza.

- (1978): «Las varillas semicilíndricas decoradas de Cueva Oscura de Ania, Las Regueras (Oviedo) »; Sautuola, Ill: 79-85.

- (1992): «Un hueso grabado de "Cueva Oscura de Ania» (Las Regueras, Asturias)»; Boletín del Instituto de Estudios Asturianos, 140: 625-650.

Rasilla VIves, Marco (1991): El Conde de la Vega del Sella y la Arqueología Prehistórica en Asturias (1870-1941); Principado de Asturias. Oviedo.

Rodriguez Asensio; J. Adolfo (1990): «Excavaciones arqueológicas realizadas en la cueva de «La Lluera» (San Juan de Priorio-Oviedo)»; Excavaciones Arqueológicas en Asturias, 1 (1983-86): 15-17.

Straus, Lawrence G. (1974): «Notas preliminares sobre el Solutrense de Asturias»; Boletín del Instituto de Estudios Asturianos, 82: 483-504.

- (1983): El Solutrense vasco-cantábrico: Una nueva perspectiva; Centro de Investigación y Museo de Altamira/Monografías, 10; Ministerio de Cultura, Madrid.

STRAUS, Lawrence G. \& CLARK, Geoffrey A. (1986): La Riera: Archaeological remains-level contents and characteristics, en Lawrence G. Straus \& Geoffrey A. ClaRK, eds.: La Riera Cave. Stone Age hunther-gatherer adaptations in Northern Spair. 75-187; Antropological Research Papers, 36; Arizona State University, Tempe.

UTRILLA MIRANDA, Pilar (1976): «La región asturiana durante los comienzos del Magdaleniense»; Boletín del Instituto de Estudios Asturianos, 88-89: 800-853.

- (1981): El Magdaleniense inferior y medio en la costa cantábrica; Centro de Investigación y Museo de Altamira/Monografías, 4; Ministerio de Cultura, Madrid.

VeGa DEL SELLA, Ricardo Duque de Estrada, Conde de la (1917): Avance al estudio del Paleolítico superior en la región asturiana, en VI Congreso de Valladolid, 1915. Anales de la Asociación Española para el Progreso de las Ciencias: 139-160; Madrid.

- (1921): El paleolítico de Cueva Morín (Santander) y Notas para la climatología cuaternaria; Comisión de Investigaciones Paleontológicas y Prehistóricas, 29; Madrid.

Vega del Sella, Ricardo Duque de Estrada, Conde de la (1930): Las cuevas de La Riera y Balmorí, Comisión de Investigaciones Paleontológicas y Prehistóricas, 38; Madrid. 